Article

\title{
Synthesis and Characterization of Renewable Polyester Coil Coatings from Biomass-Derived Isosorbide, FDCA, 1,5-Pentanediol, Succinic Acid, and 1,3-Propanediol
}

\author{
Mónica Lomelí-Rodríguez ${ }^{1, *}$, José Raúl Corpas-Martínez ${ }^{1}$, Susan Willis ${ }^{2}$, Robert Mulholland ${ }^{2}$ \\ and Jose Antonio Lopez-Sanchez ${ }^{1, * \text { (i) }}$ \\ 1 Stephenson Institute for Renewable Energy, Department of Chemistry, University of Liverpool, Crown \\ Street, Liverpool L69 7ZD, UK; Jose.Raul.Corpas-Martinez@liverpool.ac.uk \\ 2 Becker Industrial Coatings Ltd, Goodlass Road, Speke, Liverpool L24 9HJ, UK; \\ susan.willis@beckers-group.com (S.W.); Robert.Mulholland@beckers-group.com (R.M.) \\ * Correspondence: monica.lomeli.r@gmail.com (M.L.-R.); jals@liverpool.ac.uk (J.A.L.-S.); \\ Tel.: +44-(0)151-794-3535 (J.A.L.-S.)
}

Received: 20 April 2018; Accepted: 22 May 2018; Published: 29 May 2018

\begin{abstract}
Biomass-derived polyester coatings for coil applications have been successfully developed and characterized. The coatings were constituted by carbohydrate-derived monomers, namely 2,5-furan dicarboxylic acid, isosorbide, succinic acid, 1,3-propanediol, and 1,5-pentanediol, the latter having previously been used as a plasticizer rather than a structural building unit. The effect of isosorbide on the coatings is widely studied. The inclusion of these monomers diversified the mechanical properties of the coatings, and showed an improved performance against common petrochemical derived coatings. This research study provides a range of fully bio-derived polyester coil coatings with tunable properties of industrial interest, highlighting the importance of renewable polymers towards a successful bioeconomy.
\end{abstract}

Keywords: biomass; coatings; isosorbide; FDCA; polyester; biopolymer; 1-5-pentanediol

\section{Introduction}

The environmental and sustainability problems currently faced worldwide call for the implementation and usage of renewable materials across industries. Within polymers, the future in polyesters relies on the inclusion of monomers sourced from bioderived feedstocks [1]. In this vein, our group has previously developed the synthesis, kinetic modelling, and process optimization and intensification of bioderived polyesters based on furan 2,5-dicarboxylic acid (FDCA), succinic acid, 1,3-propanediol, and 1,5-pentanediol [2-4]. Common polyester coatings are normally prepared from diacids such as terephthalic acid, isophthalic acid, phthalic anhydride, and adipic acid. The polyalcohols could include difunctional monomers such as neopentyl alcohol, ethylene glycol, or polyfunctional compounds, including trimethylol propane, among other compounds exceeding two functionalities [5]. In this regard, carbohydrates are a vast source of renewable, biomass-derived diols suitable for coil coatings, such as 1,4:3,6-dianhydrohexitols [6]. Dianhydrohexitols are a by-product of the starch industry obtained by the reduction of hexose sugars followed by dehydration. 1,4:3,6-dianhydro-D-glucitol (isosorbide), 1,4:3,6-dianhydrohexitol-D-mannitol (isomannide), and 1,4:3,6-dianhydro-L-iditol (isoidide) are the three main diastereoisomers derived from D-glucose, D-mannose, and L-fructose [7], respectively, and are shown in Figure 1. The reader is encouraged to refer to additional sources for detailed information on the synthesis, chemistry, and properties of 1,4:3,6-dianhydrohexitols [8-10]. 
Isosorbide bears a considerable potential for the production of new tailored chemicals from renewable resources as it is conformed by two cis-connected tetrahydrofuran rings with secondary hydroxyl groups in the 2- (endo) and 5- (exo) positions, which allow for further functionalization or direct processing [9]. The use of isosorbide in polyesters can be motivated by several features: rigidity, chirality, non-toxicity [8], and recently, its use as a monomer for the preparation of UV-cured coatings has been highlighted [11]. Isosorbide has a relatively high thermostability and low segmental mobility, and can be used to improve the glass transition temperatures of polyesters [12]. However, the hydroxyl group in endo position easily forms intra-molecular hydrogen bonds with the oxygen in the other ring, which leads to the poor reactivity of the secondary hydroxyl group and the low number average molecular weights of copolyesters [13].

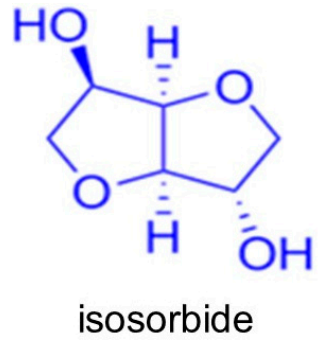

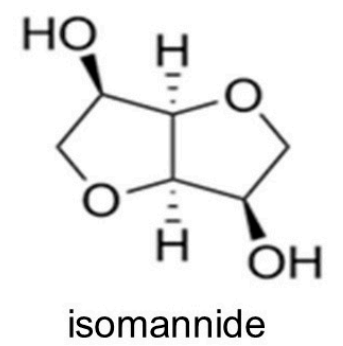

isomannide

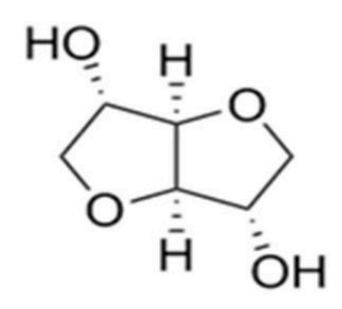

isoidide

Figure 1. Molecular structures of isosorbide, isomannide, and isoidide.

Previous work on isosorbide-based polyesters has been reported, mainly based on a variety of biomass-derived monomers, mainly citric acid [14], lactic acid [15], succinic acid [16-19], sebacic acid [17,20], itaconic acid [18], 1,4-cyclohexanedimethanol [21], and dimethyl-2,5-furan dicarboxylate [21,22]. Goerz et al. [18] studied the synthesis of polyesters from isosorbide, itaconic acid and succinic acid. The obtained polyesters had glass transition temperatures $\left(\mathrm{T}_{\mathrm{g}}\right)$ from $57^{\circ} \mathrm{C}$ to $65^{\circ} \mathrm{C}$ and molecular weights from $1200 \mathrm{Da}$ up to $3500 \mathrm{Da}$, depending on the molar ratio of the monomers. In the field of coatings, Noordover et al. $[14,19,23]$ reported the synthesis of terpolyesters for powder coatings based on isosorbide, succinic acid, citric acid, and aliphatic diols such as 1,3-propanediol, 1,4-butanediol, and neopentyl glycol, showing number average molecular weights $\left(M_{n}\right)$ from 2700 up to $4600 \mathrm{Da}$, and highlighting the effect of isosorbide content on the glass transition temperature [19]. Gioia et al. [24] synthesized polyesters based on recycled PET, succinic acid, and isosorbide for powder coating applications

Jacquel et al. [25] prepared bioderived copolyesters of succinic acid and isosorbide by varying the mol \% isosorbide from 5 to $20 \%$. The polyesters had $\mathrm{T}_{\mathrm{g}}$ from $-28^{\circ} \mathrm{C}$ to $-11^{\circ} \mathrm{C}$, which increased by increasing the $\mathrm{mol} \%$ isosorbide, while the esterification yield decreased. Zhou et al. $[12,13,20]$ studied the properties and crystallization kinetics of copolyesters based on isosorbide, sebacic acid, and either 1,10-decanediol [20] or 1,3-propanediol [12]. The authors varied the mol \% isosorbide from $5.3 \mathrm{~mol} \%$ to $66.2 \%$, reporting $\mathrm{T}_{\mathrm{g}}$ ranging from $-26^{\circ} \mathrm{C}$ to $-5^{\circ} \mathrm{C}$, although no glass transition was observed when the mol \% isosorbide was below 30\%. The $\mathrm{M}_{\mathrm{n}}$ range was broad, with the polyester of isosorbide and sebacic acid showing the lowest $\mathrm{M}_{\mathrm{n}}(2800 \mathrm{Da})$, whereas the copolyester with $25.4 \mathrm{~mol} \%$ isosorbide had the highest $M_{n}, 17000 \mathrm{Da}$. No relationship was found between the $\mathrm{M}_{n}$ and the amount of incorporated isosorbide [20].

Besides the influence of isosorbide on the final polymer, the effect of catalysts has been studied. For instance, during the synthesis of poly(ethylene terephthalate-co-isosorbide terephthalate), the authors found that combinations of antimony oxide with lithium, magnesium or aluminum based salts successfully increased the efficiency of the transesterification step [26].

Furan 2,5-dicarboxylic acid has been subject to extensive research over the last years, with a drive to develop it as a green chemical building block for polyesters [27-33]. Furan 2,5-dicarboxylic acid is a versatile, bioderived carboxylic acid which was envisioned as a replacement for terephthalic 
acid in the synthesis of poly(ethylene terephthalate) (PET) and poly(butylene terephthalate) (PBT), although many other polyfuronoates have been developed. Poly(ethylene 2,5-furandicarboxylate) (PEF) shows greatly improved barrier and mechanical properties, higher glass transition temperature, reduced oxygen permeability, and slower chain mobility than its terephthalic acid counterpart [34]. The reactivity and kinetic modelling of the catalyst effect on the PEF polycondensation reaction was also recently reported [35]. The synthesis of potentially $100 \%$ renewable FDCA copolyesters with different biomonomers has been explored as well, namely with succinic acid [2,3,30,33,36-38], 1,3-propanediol [2,39], along with some work done with copolyesters of FDCA with lactic acid [40], and isosorbide or its derivatives [21,22,25,41,42]. Tsanaktsis et al. [32] reported for the first time the synthesis of poly(pentylene furonoate) ( $\mathrm{PPeF}$ ) along with poly(heptylene furonoate) (PHepF). Poly(pentylene furonoate) was identified as a semicrystalline polyester with a melting point at $94{ }^{\circ} \mathrm{C}$, $\mathrm{T}_{\mathrm{g}}$ at $19^{\circ} \mathrm{C}$, and a maximum decomposition temperature at $394^{\circ} \mathrm{C}$. The same research group studied the thermal decomposition mechanism of PPeF, PHepF, and poly(nonylene furanoate) (PNF) [43]. The authors found that the decomposition of PPeF released gases, such as $\mathrm{CO}$ and $\mathrm{CO}_{2}$, along other degradation products such as dienes, and vinyl- and carboxyl-terminated molecules.

Lately, the thermal properties of FDCA polyesters have been extensively studied, such as poly(octylene furanoate) [44], along with thermal degradation of different polyfuronoates [45,46]. The potential of polyesters based on FDCA is steadily increasing and their industrialization and commercialization will eventually become a reality. Papageorgiou et al. [47] recently reviewed the current status and latest progress of polyfuranoates.

This research study presents the development and synthesis of new polyester resins based on isosorbide, FDCA, succinic acid, and 1,5-pentanediol to be used in coil coating applications. 1,5-pentanediol has normally been used as a polymerization additive (plasticizer) [48] rather than a main diol during poleysterification; however, we have considered it since its bioderived synthesis is playing a major role within the biorefinery concept, with promising prospects [49-54]. Resins with 1,3-propanediol are included as comparison. The paper focuses on the real applicability of the bioderived coatings instead of providing a detailed description on their compositions or chemical characterization. Instead, common mechanical testing analyses for coatings are included. Our objective is therefore to compel a fully biomass-derived, coil coatings library not only of the base polyester resins, but also of the final coatings. We believe our overall work delivers a good basis for the implementation of biomass-derived polymers in large scale and aims to become a strong industrial reference to embrace renewable feedstocks.

\section{Materials and Methods}

\subsection{Materials}

Furan 2,5-dicarboxylic acid ( $>98 \%$ ) was purchased from Manchester Organics Ltd. (Runcorn, UK) Isosorbide ( $>98 \%)$, succinic acid $(>99 \%)$, and 1,5-pentanediol $(>99 \%)$ were purchased from Acros Organics (England, UK). $\mathrm{SnCl}_{2}(>98 \%)$ was purchased from Alfa Aesar (Haverhill, MA, USA). All other chemicals were of analytical grade and obtained either from Sigma Aldrich (St. Louis, MO, USA) or Fisher Scientific (Hampton, NH, USA).

\subsection{Synthesis of Isosorbide-Based Renewable Polyesters}

The structures and the synthetic procedure of the isosorbide polyesters with 1,3-propanediol (PPFIS) and 1,5-pentanediol (PPeFIS) are depicted in Scheme 1, whereas Tables 1 and 2 summarize the polyesters synthesized, along with their $M_{n}$, weight-average molecular weight $\left(M_{w}\right)$, and dispersity (Đ), which were calculated by gel permeation chromatography (GPC), following the method described later on in Section 2. The polyesters' nomenclature is based on the diol used, the diacid molar ratio, and the molar proportion of isosorbide present. For a typical polyester, the first $P$ refers to the suffix poly, followed either by $P$ or $P e$, if synthesized with either 1,3-propanediol or 1,5-pentanediol, respectively. 
Next, the notation $F_{x}$, indicates the presence of FDCA in $x$ mol \%. Similarly, $S_{y}$ refers to the succinic acid present in $y \mathrm{~mol} \%$ whilst $I_{z}$ corresponds to the $z \mathrm{~mol} \%$ isosorbide.

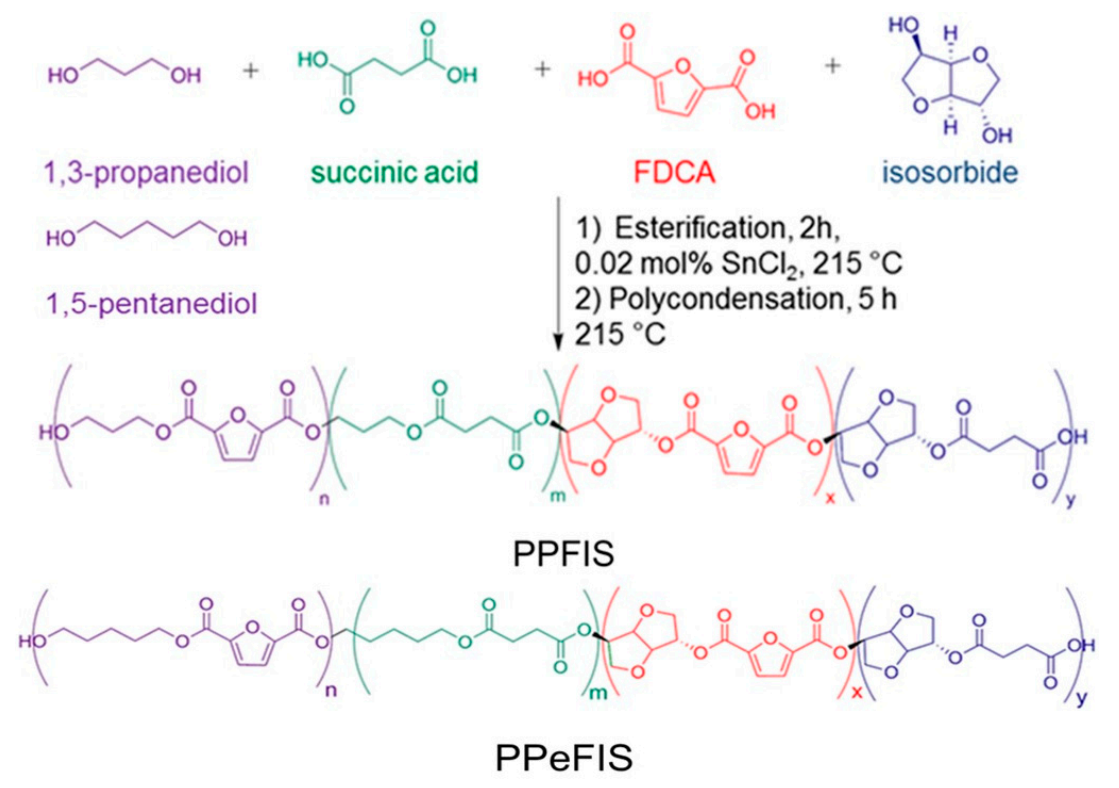

Scheme 1. Synthesis of isosorbide-based polyesters with succinic acid, furan 2,5-dicarboxylic acid (FDCA), 1,3-propanediol (PPFIS), and 1,5-pentanediol (PPeFIS).

Table 1. Synthesized biomass-derived polyesters with 1,3-propanediol and isosorbide (PPFIS).

\begin{tabular}{|c|c|c|c|c|c|c|c|}
\hline Polymer $^{a}$ & Temperature, ${ }^{\circ} \mathrm{C}$ & Mol\% FDCA & Mol\% Isosorbide & $\mathbf{R}^{\mathbf{b}}$ & $\mathrm{M}_{\mathrm{n}}, \mathrm{Da}$ & $\mathrm{M}_{\mathrm{w}}, \mathrm{Da}$ & Đ \\
\hline $\mathrm{PPF}_{15} \mathrm{I}_{30} \mathrm{~S}_{85}$ & & & 30 & & 700 & 1100 & 1.6 \\
\hline $\mathrm{PPF}_{15} \mathrm{I}_{60} \mathrm{~S}_{85}$ & 215 & 15 & 60 & 1.5 & 650 & 1000 & 1.5 \\
\hline $\mathrm{PPF}_{15} \mathrm{I}_{70} \mathrm{~S}_{85}$ & & & 70 & & 600 & 1000 & 1.5 \\
\hline $\mathrm{PPF}_{30} \mathrm{I}_{30} \mathrm{~S}_{70}$ & & & 30 & & 900 & 1500 & 1.7 \\
\hline $\mathrm{PPF}_{30} \mathrm{I}_{60} \mathrm{~S}_{70}$ & 215 & 30 & 60 & 1.5 & 600 & 1000 & 1.6 \\
\hline $\mathrm{PPF}_{30} \mathrm{I}_{70} \mathrm{~S}_{70}$ & & & 70 & & 500 & 700 & 1.3 \\
\hline $\mathrm{PPF}_{70} \mathrm{I}_{10} \mathrm{~S}_{30}$ & & & 10 & & $-c$ & & \\
\hline $\mathrm{PPF}_{70} \mathrm{I}_{30} \mathrm{~S}_{30}$ & 215 & 70 & 30 & 1.5 & $-c$ & & \\
\hline $\mathrm{PPF}_{70} \mathrm{I}_{50} \mathrm{~S}_{30}$ & & & 50 & & - & & \\
\hline $\mathrm{PPF}_{85} \mathrm{I}_{10} \mathrm{~S}_{15}$ & & & 10 & & $-c$ & & \\
\hline $\mathrm{PPF}_{85} \mathrm{I}_{30} \mathrm{~S}_{15}$ & 215 & 85 & 30 & 1.5 & - & & \\
\hline $\mathrm{PPF}_{85} \mathrm{I}_{30} \mathrm{~S}_{15}$ & & & 50 & & - & & \\
\hline
\end{tabular}

${ }^{\text {a }}$ Catalyst: $0.02 \mathrm{~mol} \% \mathrm{SnCl}_{2} / \mathrm{mol}$ diacids, ${ }^{\mathrm{b}}$ Molar ratio diols:diacids. ${ }^{\mathrm{c}}$ Polymer insoluble in tetrahydrofuran.

Polyesterification reactions were performed at two different scales: $250 \mathrm{~mL}$ and $500 \mathrm{~mL}$. The choice of scale depended on the mol \% FDCA in the feed, because the bulk viscosity of the system increased as the mol \% FDCA was increased. Hence, all the polyesters bearing furanic content above $50 \mathrm{~mol}$ $\%$ were synthesized at the $500 \mathrm{~mL}$ scale. The different scales also facilitated cleaning and recovery of the product, while minimizing the use of solvents. Despite working with two different volumes, the geometry of the stirrer and the shape of the reactor (round-bottom) were the same in both configurations, as well as the nitrogen flow rate. (No flowmeter was in place but the nitrogen flow was set to 2 bubbles $\cdot \mathrm{s}^{-1}$ ). The general polymerization reactors set-up and procedure are available in our previous publications [2-4].

The experimental synthesis was followed for all polyesters by adjusting the ratio of the monomers accordingly. The exact quantities for each polyester are available in Supplementary Material Tables S1 and S2, along with the purification polyester method. In a typical polymerization to synthesize $\mathrm{PPF}_{15} \mathrm{I}_{30} \mathrm{~S}_{85}$ to a $250 \mathrm{~mL}$ 4-neck-round bottom flask equipped with an overhead stirrer, was added $59 \mathrm{~g}$ $(0.77 \mathrm{~mol})$ of 1,3-propanediol, $48 \mathrm{~g}(0.33 \mathrm{~mol})$ of isosorbide, and $17 \mathrm{~g}(0.11 \mathrm{~mol})$ of FDCA. Secondly, 
the reactor was heated up to $150{ }^{\circ} \mathrm{C}$ and $74 \mathrm{~g}(0.62 \mathrm{~mol})$ of succinic acid and $\mathrm{SnCl}_{2}$ were added. The temperature was increased to $215^{\circ} \mathrm{C}$ and was continuously stirred at $350 \mathrm{ppm}$. The esterification stage was completed after $2 \mathrm{~h}$ when all the water had been released and the head temperature on top of the distillation column was back to ambient temperature. Then, the polycondensation reaction was carried out by azeotropic distillation by changing the packed column to a Dean Stark trap, adding $3 \mathrm{wt} \%$ xylene as azeotropic agent under atmospheric pressure for 5 hours. The reaction was finally cooled down and the polymer was collected and purified for characterization. The polyesters' color depended on the amount of FDCA and isosorbide in the mixture. Although $\mathrm{SnCl}_{2}$ was the only catalyst used, tin catalysts showed less intense coloration in a comparative polycondensation study using titanium catalysts with furanoates [35]. The intensity color range of the polyesters went from a light yellow to brown with increasing FDCA, although no color space system measurements were undertaken, as our coatings did not require any color specification.

Table 2. Synthesized biomass-derived polyesters with 1,5-pentanediol and isosorbide (PPeFIS).

\begin{tabular}{|c|c|c|c|c|c|c|c|}
\hline Polymer $^{a}$ & Temperature, C & $\operatorname{mol} \%$ FDCA & mol \% Isosorbide & $\mathbf{r}^{\mathbf{b}}$ & $\mathrm{M}_{\mathrm{n}}, \mathrm{Da}$ & $\mathrm{M}_{\mathrm{w}}, \mathrm{Da}$ & Đ \\
\hline $\mathrm{PPeF}_{15} \mathrm{I}_{10} \mathrm{~S}_{85}$ & & & 10 & & 1500 & 3100 & 2.1 \\
\hline $\mathrm{PPeF}_{15} \mathrm{I}_{30} \mathrm{~S}_{85}$ & & & 30 & & 1200 & 2500 & 2.2 \\
\hline $\mathrm{PPeF}_{15} \mathrm{I}_{50} \mathrm{~S}_{85}$ & 215 & 15 & 50 & 1.5 & 800 & 1500 & 1.8 \\
\hline $\mathrm{PPeF}_{15} \mathrm{I}_{60} \mathrm{~S}_{85}$ & & & 60 & & 500 & 1100 & 2.1 \\
\hline $\mathrm{PPeF}_{15} \mathrm{I}_{70} \mathrm{~S}_{85}$ & & & 70 & & 700 & 1100 & 1.7 \\
\hline $\mathrm{PPeF}_{30} \mathrm{I}_{10} \mathrm{~S}_{70}$ & & & 10 & & 1300 & 2700 & 2.0 \\
\hline $\mathrm{PPeF}_{30} \mathrm{I}_{30} \mathrm{~S}_{70}$ & & & 30 & & 1100 & 2800 & 2.5 \\
\hline $\mathrm{PPeF}_{30} \mathrm{I}_{50} \mathrm{~S}_{70}$ & 215 & 30 & 50 & 1.5 & 900 & 1600 & 1.9 \\
\hline $\mathrm{PPeF}_{30} \mathrm{I}_{60} \mathrm{~S}_{70}$ & & & 60 & & 500 & 700 & 1.5 \\
\hline $\mathrm{PPeF}_{30} \mathrm{I}_{70} \mathrm{~S}_{70}$ & & & 70 & & 600 & 1000 & 1.6 \\
\hline $\mathrm{PPeF}_{70} \mathrm{I}_{10} \mathrm{~S}_{30}$ & & & 10 & & 1800 & 3800 & 2.1 \\
\hline $\mathrm{PPeF}_{70} \mathrm{I}_{30} \mathrm{~S}_{30}$ & 215 & 70 & 30 & 1.5 & 1300 & 3200 & 2.4 \\
\hline $\mathrm{PPeF}_{70} \mathrm{I}_{50} \mathrm{~S}_{30}$ & & & 50 & & 1000 & 1900 & 2.0 \\
\hline $\mathrm{PPeF}_{85} \mathrm{I}_{10} \mathrm{~S}_{15}$ & & & 10 & & 2300 & 5400 & 2.3 \\
\hline $\mathrm{PPeF}_{85} \mathrm{I}_{30} \mathrm{~S}_{15}$ & 215 & 85 & 30 & 1.5 & 1300 & 2800 & 2.1 \\
\hline $\mathrm{PPeF}_{85} \mathrm{I}_{30} \mathrm{~S}_{15}$ & & & 50 & & 1000 & 1800 & 1.8 \\
\hline
\end{tabular}

${ }^{\text {a }}$ Catalyst: $0.02 \mathrm{~mol} \% \mathrm{SnCl}_{2} / \mathrm{mol}_{\text {diacids, }}{ }^{\mathrm{b}}$ Molar ratio diols:diacids.

\subsection{Characterization Methods}

\subsubsection{Nuclear Magnetic Resonance Spectroscopy $\left({ }^{1} \mathrm{H}\right.$ NMR)}

${ }^{1} \mathrm{H}$ NMR measurements were performed on a Brucker NMR spectrometer $(400 \mathrm{MHz})$. Deuterated chloroform $\left(\mathrm{CDCl}_{3}\right)$ was used as solvent for all samples.

\subsubsection{Gel Permeation Chromatography}

Gel permeation chromatography was carried out on an Agilent 1260 Infinity with two Agilent ResiPore Organic $250 \times 4.6 \mathrm{~mm}$ columns, a guard column, and a refractive index detector. The eluent was tetrahydrofuran (THF) at a flow rate of $0.3 \mathrm{~mL} / \mathrm{min}$. Molecular weights were calculated using a conventional calibration with polystyrene standards.

\subsubsection{Differential Scanning Calorimetry (DSC)}

Differential Scanning Calorimetry measurements were performed using a TA Instruments Q2000 analyzer with a RC590 cooling system using a standard heat-cool-heat method. The temperature range was $-50{ }^{\circ} \mathrm{C}$ to $200{ }^{\circ} \mathrm{C}$. Both the heating and cooling rates were $10{ }^{\circ} \mathrm{C} / \mathrm{min}$ in $\mathrm{N}_{2}$. The amount of sample was approximately $6 \pm 0.1 \mathrm{mg}$. The samples were deposited in Tzero aluminum pans. 


\subsubsection{Thermal Gravimetric Analysis (TGA)}

The thermal stability of the polyesters was determined by TGA using TA Instruments Q5000 equipment under $\mathrm{N}_{2}$ atmosphere. The samples were placed in aluminum pans and heated from room temperature to $550{ }^{\circ} \mathrm{C}$ at a rate of $10^{\circ} \mathrm{C} / \mathrm{min}$.

\subsubsection{Coatings Characterization}

Coatings were applied at 18-20 microns directly onto a smooth polyester pre-primed steel substrate and cured for $40 \mathrm{~s}$ to reach a peak metal temperature of $224-232{ }^{\circ} \mathrm{C}$. The physical testing methods carried out on the metal panels are described in Supplementary Material, Section 2 [55-61].

\section{Results and Discussion}

\section{1. ${ }^{1} H N M R$}

The intention of the present ${ }^{1} \mathrm{H}$ NMR analysis was to solely provide a general insight into the regions that identify the carbohydrate-derived polyesters. Furthermore, no quantitative analysis or precise definition of every signal was undertaken. The analysis by ${ }^{13} \mathrm{C}$ NMR and $2 \mathrm{D}$ NMR could facilitate the study. The NMR spectra of the isosorbide monomer is included in Supplementary Material, Figure S1, whilst illustrative ${ }^{13} \mathrm{C}$ NMR and 2D NMR spectra of a representative PPeFIS polyester are depicted in Figures S2 and S3.

The chemical shifts and assignments are summarized in Table 3. Figure 2 shows the NMR spectra for 1,5-pentanediol copolyesters $\mathrm{PPeF}_{85} \mathrm{I}_{10} \mathrm{~S}_{15}, \mathrm{PPeF}_{30} \mathrm{I}_{30} \mathrm{~S}_{70}$, and $\mathrm{PPeF}_{70} \mathrm{I}_{50} \mathrm{~S}_{30}$, which contain 10, 30, and $50 \mathrm{~mol} \%$ isosorbide, respectively. The identification of single peaks was a complex process since the incorporation of isosorbide could possibly facilitate the formation of cyclic structures and short chain oligomers, along with the probable presence of unreacted isosorbide (potentially between 3.5-4.5 ppm, Figure 2) at the end of the chains, leaving the secondary hydroxyl unreacted. The presence of impurities in the isosorbide monomer was a possibility as well ( $>98 \%$ purity), as it is one of the limitations of industrially-sourced isosorbide, along with residual monomer.

Table 3. Assignment of chemical shifts of PPeFIS and integrations for $\mathrm{PPeF}_{85} \mathrm{I}_{10} \mathrm{~S}_{15}$.

\begin{tabular}{|c|c|c|c|c|c|c|c|}
\hline \multirow[t]{2}{*}{ Polyester } & \multicolumn{7}{|c|}{ Assignment of Chemical Shifts $\left(\mathrm{CDCl}_{3}, \delta / \mathrm{ppm}\right)$} \\
\hline & a & $\mathrm{b}, \mathrm{b}^{\prime}$ & $\mathrm{C}$ & $\mathrm{d}$ & e & $\mathrm{f}$ & $g, j$ \\
\hline \multirow{3}{*}{ PPeFIS } & 7.20 & $2.62,2.69$ & 3.68 & $4.62-4.67$ & $3.80-3.97$ & 4.09 & 1.80 \\
\hline & $\mathrm{h}, \mathrm{k}$ & i & 1 & $\mathrm{~m}$ & $\mathrm{n}$ & o & \\
\hline & 1.66 & 4.34 & $1.42-1.48$ & $5.21-5.25$ & $4.84-4.97$ & 4.48 & $5.40-5.46$ \\
\hline \multicolumn{8}{|c|}{ Integrations for $\mathrm{PPeF}_{85} \mathrm{I}_{10} \mathrm{~S}_{15}$} \\
\hline & $\mathrm{a}$ & $b, b^{\prime}$ & c & $\mathrm{d}$ & $\mathrm{e}$ & $\mathrm{f}$ & $g, j$ \\
\hline & 2.03 & $2.00,1.13$ & 0.47 & 0.53 & 1.17 & 2.24 & 4.05 \\
\hline & $\mathrm{h}, \mathrm{k}$ & i & 1 & $\mathrm{~m}$ & $\mathrm{n}$ & o & $\mathrm{p}$ \\
\hline & 1.97 & 4.57 & 2.95 & 0.14 & 0.21 & 0.21 & 0.47 \\
\hline
\end{tabular}

The formation of the FDCA and succinic acid esters is confirmed by the shifts at 4.34 (i) and $4.09(f)$, respectively, as the protons of the FDCA esters tend to shift to higher ppm values [29-31]. The assignment $a(7.2 \mathrm{ppm})$ corresponds to the protons of the furan ring of FDCA. The signals between $3.8 \mathrm{ppm}$ and $5.4 \mathrm{ppm}(e, d, m, n, 0, p)$ are attributed to the protons of isosorbide, which is in good agreement with previous literature of different isosorbide-based polyesters: 3.9-5.6 ppm [24], 3.7-5.2 ppm [17], 3.8-5.4 ppm [20], and 3.8-5.15 ppm [19]. The differences in shifts between peaks $p$ (5.40-5.46 ppm) and $m(5.21-5.25 \mathrm{ppm})$ are the suggested result of the endo $(p)$ and exo $(m)$ stereochemistry of the two hydroxyl groups of isosorbide, as well as between peaks $d(4.62-4.67 \mathrm{ppm})$ and $n(4.84-4.97$ ppm) [19]. Gioia et al. [24] identified the endo and exo $\mathrm{OH}$ groups at $5.2 \mathrm{ppm}$ and $5.5 \mathrm{ppm}$, respectively. 
The broadening of the $\mathrm{CH}_{2}$-signal of succinic acid $\left(b\right.$ and $b^{\prime}, 2.62$ and $\left.2.69 \mathrm{ppm}\right)$ was derived from the presence of two diols, 1,5-pentanediol and isosorbide, coupled with the endo and exo stereochemistry of isosorbide. A similar behavior was reported for polyesters conformed by 1,3-propanediol and isosorbide with succinic acid, where the succinic acid shifts were observable between 2.6 and 2.8 ppm [19]. Apparently, from $\mathrm{PPeF}_{85} \mathrm{I}_{10} \mathrm{~S}_{15}$ down to $\mathrm{PPeF}_{30} \mathrm{I}_{50} \mathrm{~S}_{70}$ with $50 \mathrm{~mol} \%$ isosorbide, the characteristic peaks of 1,5-pentanediol (1.42-1.80 ppm) decrease as the isosorbide concentration increases [20], although a quantitative analysis should be performed to confirm the assumption.

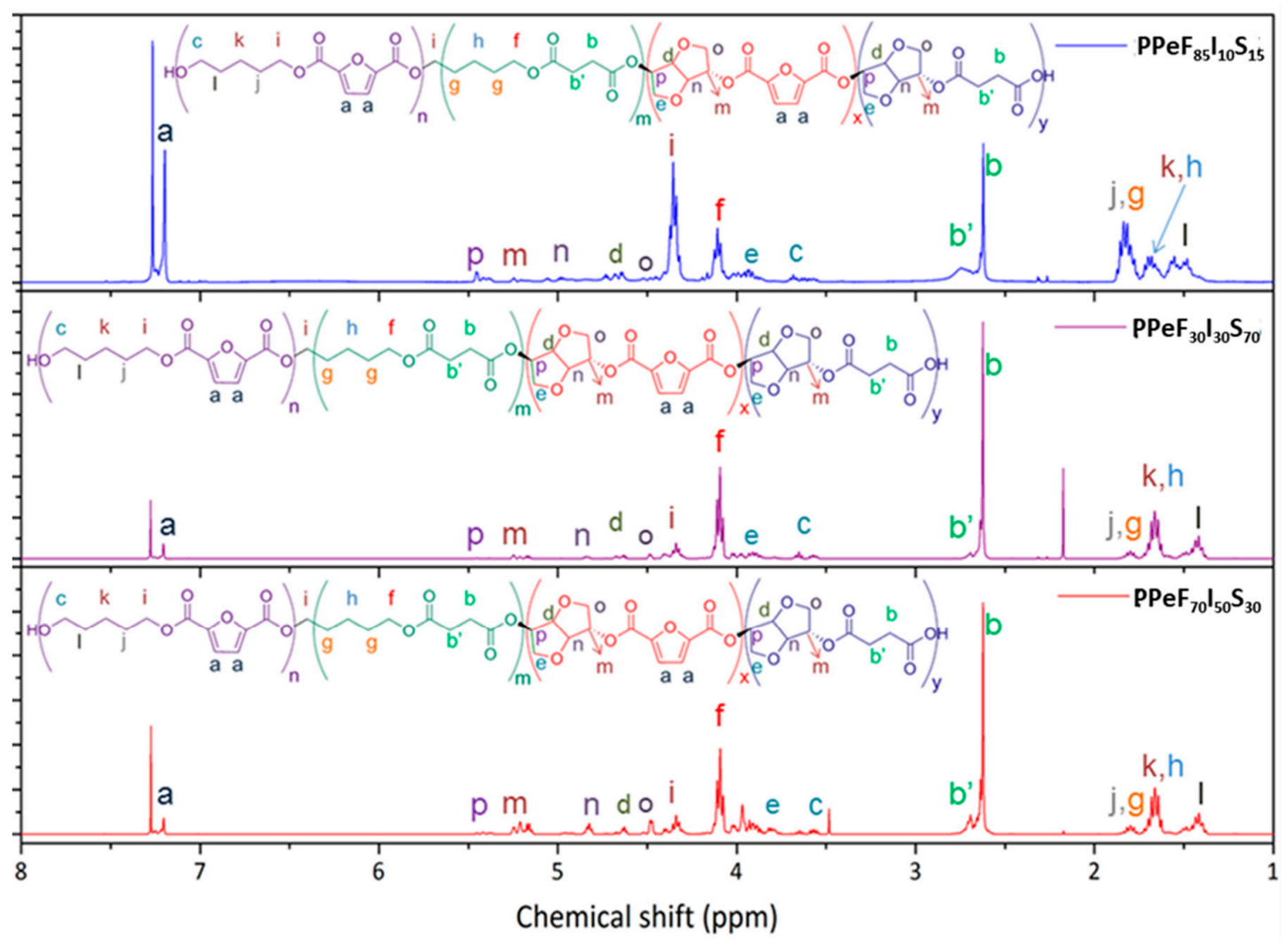

Figure 2. ${ }^{1} \mathrm{H}$ NMR spectra of $\mathrm{PPeF}_{85} \mathrm{I}_{10} \mathrm{~S}_{15}, \mathrm{PPeF}_{30} \mathrm{I}_{30} \mathrm{~S}_{70}$, and $\mathrm{PPeF}_{70} \mathrm{I}_{50} \mathrm{~S}_{30}$. The mol \% isosorbide increases from top to bottom.

\subsection{GPC}

$\mathrm{M}_{\mathrm{n}}, \mathrm{M}_{\mathrm{w}}$, and $Đ$ were measured by GPC. Tables 1 and 2 show the results obtained for the isosorbide-based polyesters, whilst Figure 3 shows the chromatographs for the $\mathrm{PPEF}_{15} \mathrm{IS}_{85}$ and $\mathrm{PPeF}_{85} \mathrm{IS}_{15}$ families, respectively.

The range of $M_{w}$ for the polyesters was between 700 and $10200 \mathrm{Da}$, whereas $\mathrm{M}_{n}$ fell within 500 and $3100 \mathrm{Da}$, indicating the great influence that the addition of isosorbide imparts, which allows a great versatility within the properties of these biomass-derived polyesters. The results obtained suggest that in general, $M_{n}$ and $M_{w}$ decreased as the isosorbide content increased. The dispersity of PPeFIS fell within 1.5/2.4 which was close to the expected value of two for polyesters [62], whilst PPFIS was between 1.3-1.6, suggesting moderate polydisperse samples. The narrowness of the distributions with isosorbide concentrations from $10 \%$ to $30 \%$ (Figures 3 and 4 ) were an indication of the strength and toughness of the polyesters. On the other hand, the narrow peaks at higher reaction times were an indication of the presence of short, oligomeric species, and potentially residual isosorbide, as previously seen in the NMR spectra. The highest $M_{n}$ and $M_{w}$ were achieved with the furan rich polyesters $\mathrm{PPeF}_{85} \mathrm{IS}_{15}$ and $\mathrm{PPeF}_{70} \mathrm{IS}_{30}$ and the trend is followed as the FDCA content decreased, although $\mathrm{PPeF}_{70} \mathrm{IS}_{30}$ had slightly higher molecular weight when the mol \% isosorbide was between 
30 and $50 \%$. The incorporation of isosorbide was limited to $50 \mathrm{~mol} \%$ for these two polyester families, as the mixture becomes extremely viscous and highly unprocessable above that concentration.
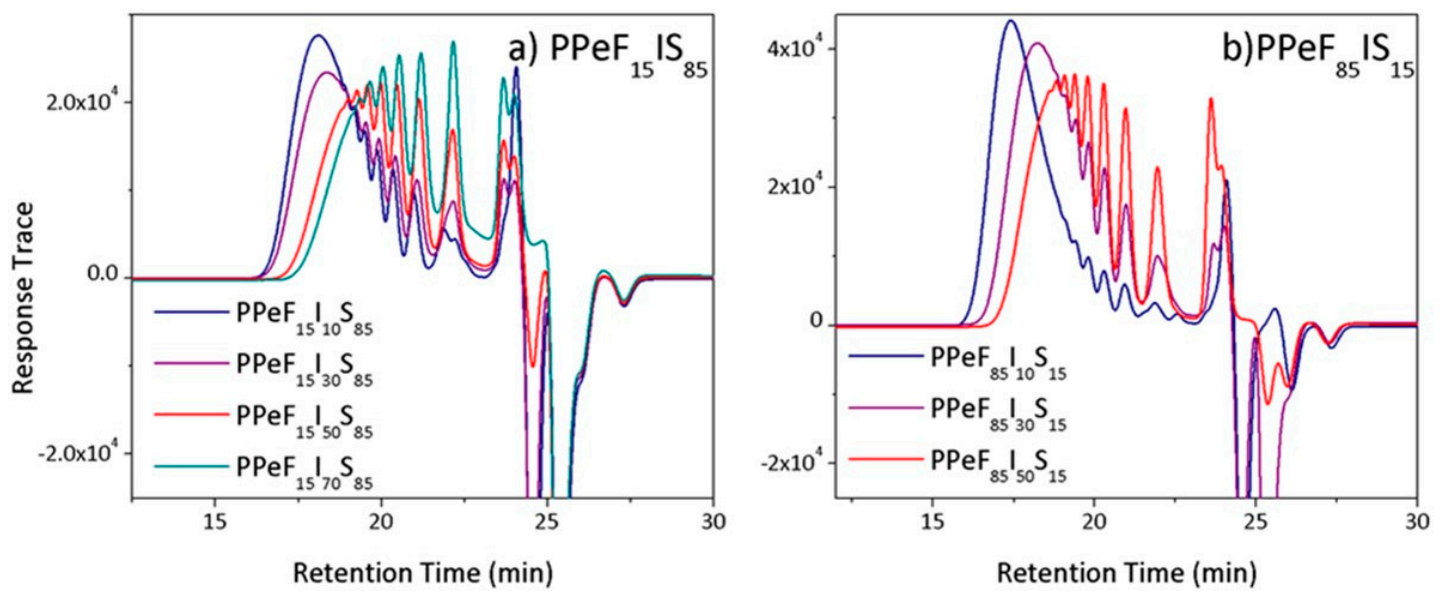

Figure 3. Gel permeation chromatography (GPC) chromatographs of (a) $\mathrm{PPeF}_{15} \mathrm{IS}_{85}$ and (b) $\mathrm{PPeF}_{85} \mathrm{IS}_{15}$.

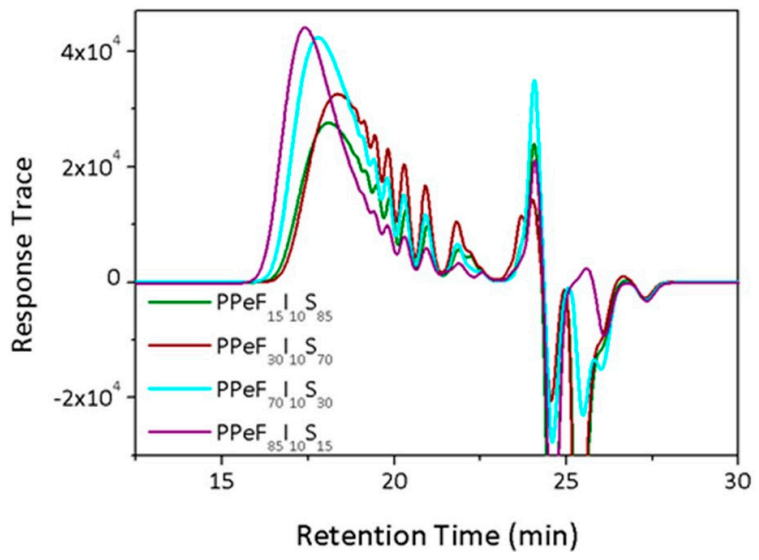

Figure 4. GPC chromatograms of polyesters PPeFIS with $10 \mathrm{~mol} \%$ isosorbide.

The molecular weight as a function of FDCA/succinic acid composition is depicted in Figure 4 for copolyesters bearing $10 \mathrm{~mol} \%$ isosorbide. The chromatograms for 30 and $50 \mathrm{~mol} \%$ isosorbide are available in Supplementary Material Figures S4 and S5.

The copolyesters $\mathrm{PPeF}_{70} \mathrm{I}_{10} \mathrm{~S}_{30}$ and $\mathrm{PPeF}_{85} \mathrm{I}_{10} \mathrm{~S}_{15}$ with $10 \mathrm{~mol} \%$ isosorbide presented $\mathrm{M}_{\mathrm{W}}$ of $3800 \mathrm{Da}$ and $5400 \mathrm{Da}$, respectively and the dispersities of both compositions with different $\mathrm{mol} \%$ isosorbide were above two. These values represent the highest molecular weights among the copolyesters of FDCA and succinic acid with isosorbide, whereas the lowest $\mathrm{M}_{\mathrm{W}}$ figures correspond to $\mathrm{PPeF}_{15} \mathrm{IS}_{85}$ and $\mathrm{PPeF}_{30} \mathrm{IS}_{70}$ with either 60 or $70 \mathrm{~mol} \%$ isosorbide (1000 Da). In the case of $\mathrm{PPeF}_{15} \mathrm{IS}_{85}$ and $\mathrm{PPeF}_{30} \mathrm{IS}_{70}$, dispersities of two and $\mathrm{M}_{\mathrm{w}}$ above $2000 \mathrm{Da}$ were obtained when the isosorbide content was limited to $30 \%$.

The results for PPFIS resembled our findings with PPeFIS copolyesters. It was observed that $M_{n}$ decreases as isosorbide content increases, for all compositions. The chromatograms of $\mathrm{PPF}_{15} \mathrm{IS}_{85}$ and $\mathrm{PPF}_{30} \mathrm{IS}_{70}$ are available in Supplementary Material Figure S6. Unfortunately, the results for $\mathrm{PPF}_{70} \mathrm{IS}_{30}$ and $\mathrm{PPF}_{85} \mathrm{IS}_{15}$ are not available since the samples were insoluble in THF.

The decrease in $\mathrm{M}_{\mathrm{n}}$ as the isosorbide content increases has been reported in the literature $[12,15,19,20,63]$. One of the possible explanations was the decreased reactivity of the secondary OH groups when compared with the primary $\mathrm{OH}$ groups present in aliphatic linear diols, possibly corresponding to 
a lower acidic character [24], and most importantly, nucleophilicity. Nucleophilicity is affected by steric hindrance, since the bulkier a given nucleophile is, the slower the rate of its reactions and therefore the lower its nucleophilicity. In the case of isosorbide, although the nucleophilicity of the endo hydroxyl group is increased, the steric hindrance caused by hydrogen bonding makes the exo hydroxyl group more reactive [64]. Consequently, the difference in reactivity of the $\mathrm{OH}$ groups present in isosorbide was mainly due to their stereochemical nature-endo and exo-where the steric hindrance of the endo hydroxyl group is known to decrease the whole reactivity of the system [24]. The $\mathrm{OH}$ in endo position is more likely to form intra-molecular hydrogen bonding with the oxygen in main chains, while the other in exo position is more reactive in polycondensation reactions [65]. In addition, the endo hydroxyl is protected by the steric bulk of the rest of the molecule [66]. It might be worthwhile to do a kinetic study to explore different catalysts and reaction times and their influence on the final molecular weight of the polyesters. Wei et al. [20] showed that increasing the isosorbide content above 30\% resulted in a significant decrease in the number average molecular weights of the polyesters. In fact, the $M_{n}$ of the homopolymer poly(isosorbide sebacate) was lower than $3000 \mathrm{Da}$. Sadler et al. [63] synthesized unsaturated polyesters of phthalic anhydride, maleic anhydride, ethylene glycol, and isosorbide. The polyesters had isosorbide contents from 10 to $25 \mathrm{~mol} \%$, and the molecular weight decreased accordingly from 7000 to $3500 \mathrm{Da}$. In the same vein, Noordover et al. [19] reported $\mathrm{M}_{\mathrm{n}}$ from 2000 to $3100 \mathrm{Da}$ for polyesters of succinic acid and isosorbide, and $\mathrm{M}_{\mathrm{n}}$ from 2700 to $4600 \mathrm{Da}$ with the addition of 1,4-butanediol or neopentyl glycol as the second diol monomer. Our results suggest that the incorporation of more than $50 \mathrm{~mol} \%$ isosorbide when processing via azeotropic distillation is considerably detrimental to the molecular weight of the polyesters, even though a catalyst is added to the reaction mixture. This could be due either to changes in stoichiometry, so more hydroxyl functionality will reduce the molecular weight, or due to the isosorbide reacting as a mono-functional monomer. If the isosorbide content is kept between 10 and $30 \mathrm{~mol} \%$, the molecular weights are in the desirable range for coatings (i.e., 2000 to $6000 \mathrm{Da}$ ) [5,19].

\subsection{DSC}

The DSC scans for $\mathrm{PPeF}_{30} \mathrm{IS}_{70}$ and $\mathrm{PPeF}_{70} \mathrm{IS}_{30}$ are shown in Figure 5, whilst the $\mathrm{T}_{\mathrm{g}}$, melting temperatures $\left(\mathrm{T}_{\mathrm{m}}\right)$, and the melting enthalpies $\left(\Delta \mathrm{H}_{\mathrm{m}}\right)$ are summarized in Table 4 . The $\mathrm{T}_{\mathrm{g}}$ of the parent resins with no isosorbide is included as reference. The isosorbide content and glass transition temperature kept a linear relationship as expected. In all the different compositions, the $\mathrm{T}_{\mathrm{g}}$ increased as a function of the $\mathrm{mol} \%$ isosorbide. Sadler et al. [63] demonstrated that adding as little as $10 \mathrm{~mol} \%$ isosorbide to the reaction mixture in place of an equivalent amount of a linear diol resulted in a significant increase in $\mathrm{T}_{\mathrm{g}}$. Moreover, adding 60 and $80 \mathrm{~mol} \%$ isosorbide to resins based on succinic acid and neopentyl glycol achieved final glass transition temperatures from $30.5^{\circ} \mathrm{C}$ and $47.1{ }^{\circ} \mathrm{C}$, respectively [19].

Within the range of molecular weights of the resins and taking into account the diacid composition of the base polyester, a minimum content of $50 \mathrm{~mol} \%$ isosorbide was needed in order to achieve glass transition temperatures above $0{ }^{\circ} \mathrm{C}$ and above room temperature. The copolyesters $\mathrm{PPeF}_{70} \mathrm{IS}_{30}$ and $\mathrm{PPeF}_{85} \mathrm{IS}_{15}$ exhibited the highest $\mathrm{T}_{\mathrm{g}}$ among the 1,5-pentanediol polyesters, achieving values of $31^{\circ} \mathrm{C}$ and $22{ }^{\circ} \mathrm{C}$, respectively. Surprisingly, $\mathrm{PPeF}_{70} \mathrm{I}_{50} \mathrm{~S}_{30}$ had higher $\mathrm{T}_{\mathrm{g}}\left(31^{\circ} \mathrm{C}\right)$ than $\mathrm{PPeF}_{85} \mathrm{I}_{50} \mathrm{~S}_{15}\left(22{ }^{\circ} \mathrm{C}\right)$, with $50 \mathrm{~mol} \%$ isosorbide, but when only $10 \mathrm{~mol} \%$ was added, the difference in respect to the base polyester is either negligible $\left(-1{ }^{\circ} \mathrm{C}\right.$ for $\mathrm{PPeF}_{70} \mathrm{I}_{10} \mathrm{~S}_{30}$ and $-10{ }^{\circ} \mathrm{C}$ for $\mathrm{PPeF}_{70} \mathrm{~S}_{30}$ ) or very little as per $85 \mathrm{~mol} \% \mathrm{FDCA}\left(4^{\circ} \mathrm{C}, \mathrm{PPeF}_{85} \mathrm{I}_{10} \mathrm{~S}_{15}\right.$ and $\left.1{ }^{\circ} \mathrm{C}, \mathrm{PPeF}_{85} \mathrm{~S}_{15}\right)$. Nonetheless, the slight difference might not be significant and could come down to the acid value that was processed.

For the succinic acid rich polyesters $\mathrm{PPeF}_{15} \mathrm{IS}_{85}$ and $\mathrm{PPeF}_{30} \mathrm{IS}_{70}$, there is an abrupt increase in the glass transition temperature when the isosorbide content is $60 \%$ or above, going from values of approximately $-40^{\circ} \mathrm{C}$ up to $30^{\circ} \mathrm{C}$. This suggests that our library of polyester resins, based in three main monomers, would have different end properties just by tuning the desired content of isosorbide, expanding the potential applications of our renewable coatings. Figure 6 shows $T_{g}$ and $M_{n}$ as a 
function of isosorbide content for $\mathrm{PPeF}_{70} \mathrm{IS}_{30}$ and $\mathrm{PPeF}_{85} \mathrm{IS}_{15}$. The corresponding $\mathrm{M}_{\mathrm{n}}-\mathrm{T}_{\mathrm{g}}$-isosorbide relationships for $\mathrm{PPeF}_{15} \mathrm{IS}_{85}$ and $\mathrm{PPeF}_{30} \mathrm{IS}_{70}$ are depicted in Figures $\mathrm{S} 10$ and S11, Supplementary Material. It is observed how $\mathrm{M}_{n}$ decreases as the isosorbide content increases, as explained in the GPC section.
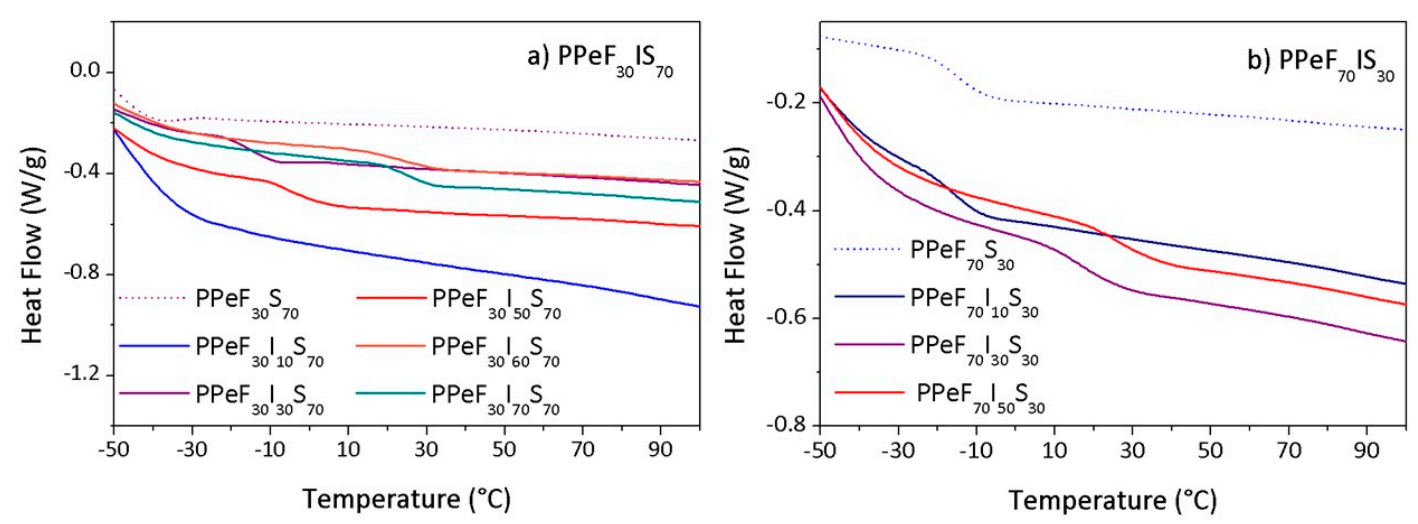

Figure 5. Second heating scan at $10{ }^{\circ} \mathrm{C} / \mathrm{min}$ for polyesters (a) $\mathrm{PPeF}_{30} \mathrm{IS}_{70}$ including $\mathrm{PPeF}_{30} \mathrm{~S}_{70}$ as the no-isosorbide reference and (b) $\mathrm{PPeF}_{70} \mathrm{IS}_{30}$ including $\mathrm{PPeF}_{70} \mathrm{~S}_{30}$ as the no-isosorbide reference.

Table 4. Thermal transitions of PPeFIS polyesters measured by differential scanning calorimetry (DSC).

\begin{tabular}{cccccc}
\hline Polyester & Mol\% Isosorbide & $\mathbf{M}_{\mathbf{w}}, \mathbf{D a}$ & $\mathbf{T}_{\mathbf{g}}{ }^{\circ} \mathbf{C}$ & $\mathbf{T}_{\mathbf{m}} \boldsymbol{\prime}{ }^{\circ} \mathbf{C}$ & $\Delta \mathbf{H}_{\mathbf{m}} \mathbf{J} \mathbf{J} \mathbf{g}$ \\
\hline $\mathrm{PPeF}_{15} \mathrm{~S}_{85}$ & 0 & 2700 & -46 & - & - \\
$\mathrm{PPeF}_{15} \mathrm{I}_{10} \mathrm{~S}_{85}$ & 10 & 3100 & -43 & - & - \\
$\mathrm{PPeF}_{15} \mathrm{I}_{30} \mathrm{~S}_{85}$ & 30 & 2500 & -26 & - & - \\
$\mathrm{PPeF}_{15} \mathrm{I}_{50} \mathrm{~S}_{85}$ & 50 & 1500 & -12 & - & - \\
$\mathrm{PPeF}_{15} \mathrm{I}_{60} \mathrm{~S}_{85}$ & 60 & 1100 & 7 & - & - \\
$\mathrm{PPeF}_{15} \mathrm{I}_{70} \mathrm{~S}_{85}$ & 70 & 1100 & 35 & 117 & 2.6 \\
$\mathrm{PPeF}_{30} \mathrm{~S}_{70}$ & 0 & 2800 & -39 & - & - \\
$\mathrm{PPeF}_{30} \mathrm{I}_{10} \mathrm{~S}_{70}$ & 10 & 2600 & -39 & - & - \\
$\mathrm{PPeF}_{30} \mathrm{I}_{30} \mathrm{~S}_{70}$ & 30 & 2800 & -12 & 155 & 3.5 \\
$\mathrm{PPeF}_{30} \mathrm{I}_{50} \mathrm{~S}_{70}$ & 50 & 1600 & 0.7 & 139 & 1.3 \\
$\mathrm{PPeF}_{30} \mathrm{I}_{60} \mathrm{~S}_{70}$ & 60 & 700 & 23 & 105 & 0.1 \\
$\mathrm{PPeF}_{30} \mathrm{I}_{70} \mathrm{~S}_{70}$ & 70 & 1000 & 24 & 77 & - \\
$\mathrm{PPeF}_{70} \mathrm{~S}_{30}$ & 0 & 5900 & -10 & - & - \\
$\mathrm{PPeF}_{70} \mathrm{I}_{10} \mathrm{~S}_{30}$ & 10 & 3800 & -11 & - & - \\
$\mathrm{PPeF}_{70} \mathrm{I}_{30} \mathrm{~S}_{30}$ & 30 & 3200 & 19 & 94 & 0.4 \\
$\mathrm{PPeF}_{70} \mathrm{I}_{50} \mathrm{~S}_{30}$ & 50 & 1900 & 31 & 105 & 1.2 \\
$\mathrm{PPeF}_{85} \mathrm{~S}_{15}$ & 0 & 4100 & 1 & 50 & - \\
$\mathrm{PPeF}_{85} \mathrm{I}_{10} \mathrm{~S}_{15}$ & 10 & 5400 & 4 & 119 & 0.1 \\
$\mathrm{PPeF}_{85} \mathrm{I}_{30} \mathrm{~S}_{15}$ & 30 & 2800 & 20 & 101 & 1.0 \\
$\mathrm{PPeF}_{85} \mathrm{I}_{50} \mathrm{~S}_{15}$ & 50 & 1800 & 22 & 139 & 1.4 \\
\hline
\end{tabular}

Nevertheless, some other factors, such as impurities, chemical conformation, degree of crystallinity, and molecular weight could be relevant for the analysis of thermal transitions. Consequently, further work could be focused on the particular effect of any of the above factors for selected polyesters, potentially those with closer molar masses or bearing the greatest industrial feasibility.

The glass transition temperatures of the PPFIS family, prepared with 1,3-propanediol, are slightly higher since they present lower chain flexibility than their 1,5-pentanediol counterparts. The results are available in Supplementary Material Table S3. The inclusion of $30 \mathrm{~mol} \%$ isosorbide leads to an increase of $\mathrm{T}_{\mathrm{g}}$ of about $30^{\circ} \mathrm{C}\left(-45^{\circ} \mathrm{C}\right.$ to $\left.-14^{\circ} \mathrm{C}\right)$ achieving a $\mathrm{T}_{\mathrm{g}}$ at $6.2{ }^{\circ} \mathrm{C}$ with $70 \mathrm{~mol} \%$ isosorbide. The copolyesters $\mathrm{PPF}_{70} \mathrm{I}_{50} \mathrm{~S}_{30}$ and $\mathrm{PPF}_{85} \mathrm{I}_{50} \mathrm{~S}_{15}$ with $50 \mathrm{~mol} \%$ isosorbide exhibited the highest $\mathrm{T}_{\mathrm{g}}$ among all the polyesters, achieving values of 29.2 and $53.2^{\circ} \mathrm{C}$, respectively. Representative DSC thermograms of PPFIS polyesters are available in Supplementary Material Figures S7 and S8. 

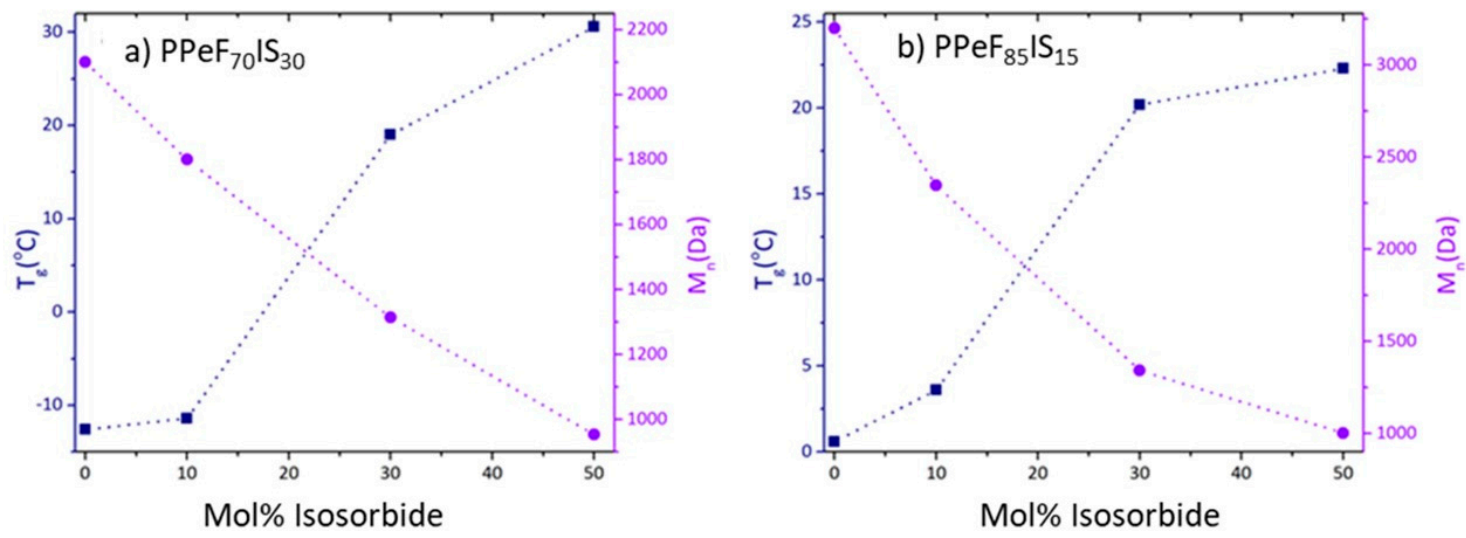

Figure 6. $T_{g}$ and $M_{n}$ as a function of mol \% isosorbide for (a) $\mathrm{PPeF}_{70} \mathrm{IS}_{30}$ and (b) $\mathrm{PPeF}_{85} \mathrm{IS}_{15}$.

Tailoring the different ratios of diacids and diols allowed to synthesize amorphous and semicrystalline polyesters. Regarding melting temperatures $\left(T_{m}\right)$ 1,5-pentanediol polyesters with FDCA contents of $30 \%$ and above showed melting endotherms from $77.3{ }^{\circ} \mathrm{C}$ to $154.7^{\circ} \mathrm{C}$, whereas for 1,3-propanediol the only observable Tm's $\left(97-131^{\circ} \mathrm{C}\right.$ ) correspond to those containing 70 and $85 \mathrm{~mol} \%$ FDCA. In the case of $\mathrm{PPF}_{85} \mathrm{IS}_{15}$ and $\mathrm{PPeF}_{30} \mathrm{IS}_{70}, \mathrm{~T}_{\mathrm{m}}$ decreased with an increase of the isosorbide content, a phenomenon that was previously observed in copolyesters of sebacic acid, 1,3-propanediol, and varying isosorbide content [12], whereas the other compositions exhibit the opposite trend.

Particularly, polyesters $\mathrm{PPF}_{70} \mathrm{IS}_{30}$ and $\mathrm{PPF}_{85} \mathrm{IS}_{15}$ did not show a single melting peak in the DSC heating scan, as observed in Figure 7 for $\mathrm{PPF}_{85} \mathrm{IS}_{15}$ and Figure S9 for $\mathrm{PPF}_{70} \mathrm{IS}_{30}$. This behavior has been reported in the literature [12,67-69] for different copolyesters, and it is thought to be potentially the result of the existence of different crystal types in the same polymer sample [67], melting-recrystallization-remelting processes $[68,70,71]$, or the presence of different molecular weight species [12]. It is necessary to confirm the assumptions regarding crystallinity features by performing an X-Ray Diffraction (XRD) analysis of the polyesters. There is a strong possibility that the polyesters are conformed by different oligomers with varying molecular weights, as the presence of isosorbide tends to form cyclic oligomeric structures [19,72]. Again, the confirmation of these structures requires further robust analysis, such as MALDI-TOF-MS, although this is outside our current scope.

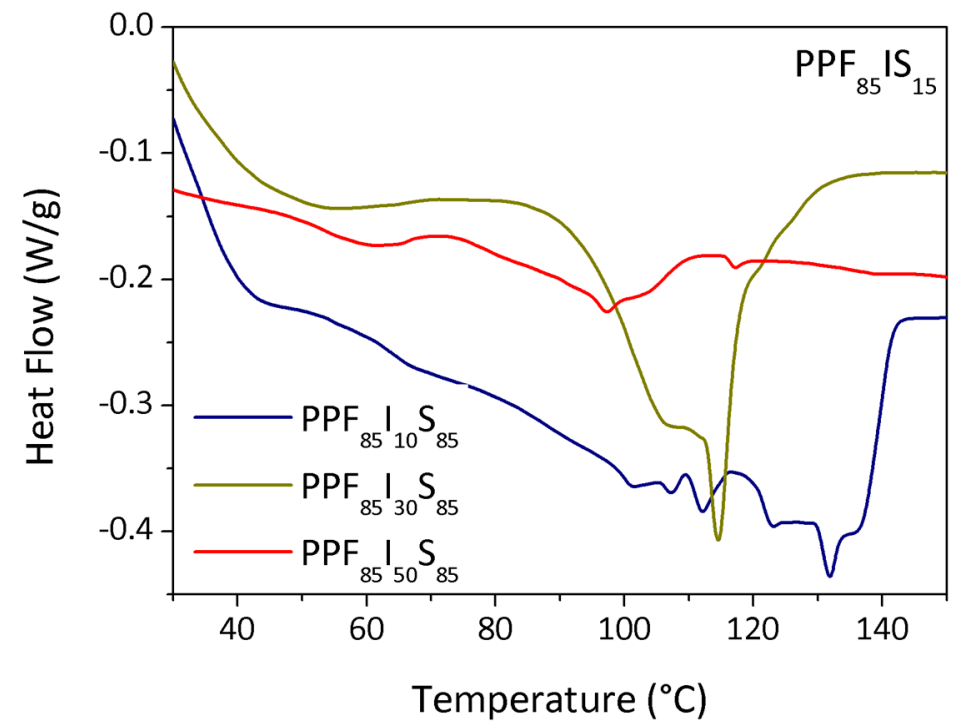

Figure 7. First heating scan at $10^{\circ} \mathrm{C} / \mathrm{min}$ for polyesters $\mathrm{PPF}_{85} \mathrm{I}_{10} \mathrm{~S}_{15}, \mathrm{PPF}_{85} \mathrm{I}_{30} \mathrm{~S}_{15}$, and $\mathrm{PPF}_{85} \mathrm{I}_{50} \mathrm{~S}_{15}$. 
Previous syntheses of isosorbide-derived polyesters have reported glass transition temperatures in the range presented herein or below. For instance, the $T_{g}$ 's of poly(isosorbide sebacate) and poly(isosorbide itaconate) were $6.4^{\circ} \mathrm{C}\left(\mathrm{M}_{\mathrm{n}}=19200 \mathrm{Da}\right)$ and $34.5^{\circ} \mathrm{C}\left(\mathrm{M}_{\mathrm{n}}=8700 \mathrm{Da}\right)$, respectively [17]. Wei et al. [20] synthesized polyesters of 1,10-decanediol, sebacic acid and isosorbide with different mol $\%$ isosorbide, namely, $43.9 \%, 66.2 \%$, and $100 \%$. The polyesters showed $\mathrm{T}_{\mathrm{g}}{ }^{\prime} \mathrm{s}$ at $-26{ }^{\circ} \mathrm{C},-18{ }^{\circ} \mathrm{C}$, and $-5{ }^{\circ} \mathrm{C}$, with $\mathrm{M}_{\mathrm{w}}=8900,8699$, and $2800 \mathrm{Da}$, respectively. The authors did not observe glass transitions for 5.3 or $16.7 \mathrm{~mol} \%$ isosorbide, which they attributed to the fact that long chain aliphatic polyesters have a strong crystallization capacity and crystallize very fast. Terzopoulou and coworkers [22] showed that poly(isosorbide-2,5-furanoate) presented a $\mathrm{Tg}$ at $157^{\circ} \mathrm{C}$, whilst the Tg's for copolyesters of FDCA, isosorbide, and 1,4-cyclohexane-dimethanol (CHDM) increased from 75.3 to $103.5^{\circ} \mathrm{C}$, with decreasing $\mathrm{CHDM} /$ isosorbide ratios from $95 / 5$ to $60 / 40$ [21].

\subsection{TGA}

Figure 8 shows the thermograms for the polyesters $\mathrm{PPeF}_{70} \mathrm{IS}_{30}$ and $\mathrm{PPeF}_{85} \mathrm{IS}_{15}$. Thermal gravimetric analysis indicates that the thermal stability ranges from $308^{\circ} \mathrm{C}$ to $371{ }^{\circ} \mathrm{C}$ for the 1,5 -pentanediol library. Expectedly, PPFIS polyesters showed a slightly higher and narrower $T_{d}$ range between 362 and $372{ }^{\circ} \mathrm{C}$, suggesting that the diol is a fundamental factor for thermal stability. Previous studies have shown that the thermal stability decreases with increasing methylene units. For example, the Bikiaris group [43] showed that poly(1,4-butylene furanoate) (PBF) was less thermally stable than the furanoates synthesized with shorter chain diols, such as ethylene glycol and 1,3-propanediol. The thermal decomposition temperatures $\left(\mathrm{T}_{\mathrm{d}}\right)$ for PPeFIS and PPFIS are summarized in Tables $\mathrm{S} 4$ and S5 in Supplementary Material, along with the TGA thermograms of $\mathrm{PPeF}_{15} \mathrm{IS}_{85}$ and $\mathrm{PPeF}_{30} \mathrm{IS}_{70}$, which correspond to Figure S12.
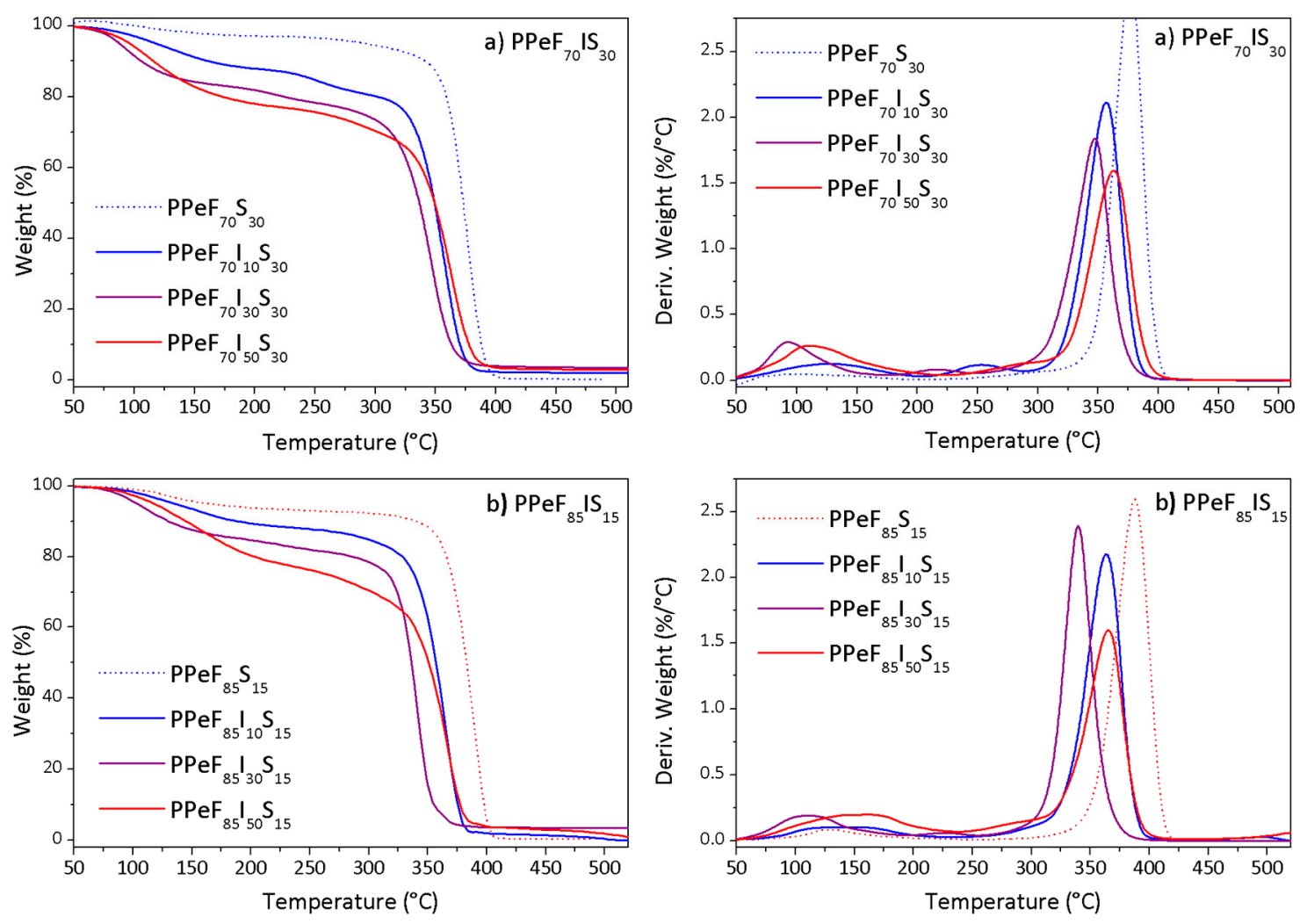

Figure 8. Weight $\%$ and derivative weight thermograms of polyesters (a) $\mathrm{PPeF}_{70} \mathrm{IS}_{30}$ and (b) $\mathrm{PPeF}_{85} \mathrm{IS}_{15}$ $\left(\mathrm{N}_{2}\right.$ flow, $\left.10^{\circ} \mathrm{C} \cdot \mathrm{min}^{-1}\right)$. 
For both linear aliphatic diols, the incorporation of isosorbide to the main polymers resulted in a decrease of approximately $30-40{ }^{\circ} \mathrm{C}$ in the maximum $\mathrm{T}_{\mathrm{d}}$ of the resins, which were close $\left(\sim 385^{\circ} \mathrm{C}\right)$ or above $400{ }^{\circ} \mathrm{C}$. Within each diacidcomposition, the results suggest that the PPeFIS polyesters with highest $\mathrm{mol} \%$ isosorbide present the highest decomposition temperature. However, the same trend was not observed for PPFIS, where all the polyesters had similar $T_{d}$ values.

Specifically, for 1,3-propanediol, the thermogravimetric data suggests the presence of diverse species within the polymer matrix, as three different decomposition temperatures $\left(\mathrm{T}_{\mathrm{d} 1}, \mathrm{~T}_{\mathrm{d} 2}\right.$, and $\mathrm{T}_{\mathrm{dmax}}$, Table S5) are observed. All the diacid compositions present the first decomposition temperature between $98.7^{\circ} \mathrm{C}$ and $194{ }^{\circ} \mathrm{C}$, followed by a second transition at $180-290^{\circ} \mathrm{C}$. The lowest $\mathrm{T}_{\mathrm{d}}{ }^{\prime} \mathrm{s}$ appear to be prompted by isosorbide concentrations of above $50 \mathrm{~mol} \%$. The nature of these species has not been determined; however, previous research has shown that polyesters undergo decomposition mechanisms initiated by scission of an alkyl-oxygen bond, suggesting a random-chain scission [73]. Also, the decomposition of these polyesters is suggested to be dominated by cyclic or open chain oligomers with carboxylic-end groups. The formation of these cyclic oligomers is done through an intramolecular exchange reaction which happens below $300^{\circ} \mathrm{C}[74]$ which could be the same process that took place in our polyesters. Cyclization of isosorbide-based polyesters has indeed been reported by other authors $[15,19]$. In the case of polyesters with low FDCA and rich isosorbide contents, data suggests the formation of more volatile products, which some authors have determined to arise from the secondary breakdown of end-groups, which follows the primary step of cyclic concerted decomposition [75].

\subsection{Coatings}

Tables 5 and 6 summarize the results obtained. For succinic acid-rich polyesters, the chosen samples were those with higher isosorbide concentrations. A reference, petro-derived coating $R$ has been included for comparison. Specifically, in the case of 1,3-propanediol resins, it was not possible to make paints with $\mathrm{PPF}_{15} \mathrm{I}_{70} \mathrm{~S}_{85}$ and $\mathrm{PPF}_{30} \mathrm{I}_{70} \mathrm{~S}_{70}$ (70 mol \% isosorbide) as they were immiscible with the paint solvent system, which consisted of a 50:50 mixture of butanol and dibasic ester. In the case of $\mathrm{PPF}_{70} \mathrm{I}_{50} \mathrm{~S}_{30}$, the resin was a brittle solid, which prevented solution in the same paint solvents. As similarly reported for some coating applications $[14,19,24,63]$, the introduction of isosorbide into the synthesis of the polyester resins improved the thermomechanical properties of the resulting paints, compared to the parent polyesters. The no-isosorbide parent polyesters, $\mathrm{PPeF}_{5} \mathrm{~S}_{85}$ and $\mathrm{PPeF}_{30} \mathrm{~S}_{70}$, had very low microhardness $\left(11 \mathrm{~N} \cdot \mathrm{m}^{-2}\right.$ and $12 \mathrm{~N} \cdot \mathrm{m}^{-2}$, respectively) and low $\mathrm{T}_{\mathrm{g}}\left(-28^{\circ} \mathrm{C}\right.$ and -17 ${ }^{\circ} \mathrm{C}$, respectively), but when $70 \mathrm{~mol} \%$ isosorbide was added $\left(\mathrm{PPeF}_{15} \mathrm{I}_{70} \mathrm{~S}_{85}\right.$ and $\left.\mathrm{PPeF}_{0} \mathrm{I}_{70} \mathrm{~S}_{70}\right)$ the microhardness abruptly increased to $237 \mathrm{~N} \cdot \mathrm{m}^{-2}$ and $287 \mathrm{~N} \cdot \mathrm{m}^{-2}$, with $\mathrm{T}_{\mathrm{g}}$ at $66^{\circ} \mathrm{C}$ and $53^{\circ} \mathrm{C}$. The resins were not very flexible as T-Bend was $5 \mathrm{~T}$ and $6 \mathrm{~T}$ and both presented severe cracking after the Erichsen testing, which suggested that the concentration of FDCA should be increased. We previously reported the effect of the FDCA on the final polyester resin [2]. $\mathrm{PPeF}_{70} \mathrm{I}_{30} \mathrm{~S}_{30}$ with an isosorbide concentration of $30 \mathrm{~mol} \%$ and an increased FDCA concentration of $70 \%$ showed an improvement in flexibility (2.5T) respect to the reference resin (3T), $\mathrm{T}_{\mathrm{g}}$ on specification at $34^{\circ} \mathrm{C}$ and better impact resistance as it presented a slight cracking. Moreover, $\mathrm{PPeF}_{70} \mathrm{I}_{50} \mathrm{~S}_{30}$ had above-specification Erichsen (No cracking), $\mathrm{T}_{\mathrm{g}}\left(67^{\circ} \mathrm{C}\right)$ and microhardness $\left(270 \mathrm{~N} \cdot \mathrm{m}^{-2}\right)$ than the reference resin. Likewise, comparing $\mathrm{PPeF}_{70} \mathrm{I}_{50} \mathrm{~S}_{30}$ with its parent resin with no isosorbide, the performance was considerably improved, as the properties recorded for the latter were $\mathrm{T}_{\mathrm{g}}=6^{\circ} \mathrm{C}$, Microhardness $=20 \mathrm{~N} \cdot \mathrm{m}^{-2}$ and T-Bend no cracking of 1.5T.

$\mathrm{PPeF}_{85} \mathrm{IS}_{15}$ resins again showed better microhardness and higher $\mathrm{T}_{\mathrm{g}}$ than $\mathrm{PPeF}_{85} \mathrm{~S}_{15}$, as the results were $21 \mathrm{~N} \cdot \mathrm{m}^{-2}$ and $15^{\circ} \mathrm{C}$, respectively. $\mathrm{PPeF}_{85} \mathrm{I}_{50} \mathrm{~S}_{15}$ (Table 6), despite having the highest $\mathrm{T}_{\mathrm{g}}\left(69^{\circ} \mathrm{C}\right.$ ) and enhanced microhardness $\left(299 \mathrm{~N} \cdot \mathrm{m}^{-2}\right.$ ) was slightly harder (Pencil Hardness $2 \mathrm{H}$ ) and presents poor flexibility measured by T-Bend no cracking (5.5T). $\mathrm{PPeF}_{85} \mathrm{I}_{30} \mathrm{~S}_{15}$ therefore presented the best overall properties (Table 6). 
Table 5. Physical test results on white paints based on polyesters $\mathrm{PPeF}_{15} \mathrm{IS}_{85}-\mathrm{PPeF}_{70} \mathrm{IS}_{30}$ and the standard reference resin $\mathrm{R}$.

\begin{tabular}{|c|c|c|c|c|c|c|}
\hline Test & Standard & $\mathbf{R}$ & $\mathrm{PPeF}_{15} \mathrm{I}_{70} \mathrm{~S}_{85}$ & $\mathrm{PPeF}_{30} \mathrm{I}_{70} \mathrm{~S}_{70}$ & $\mathrm{PPeF}_{70} \mathrm{I}_{30} \mathrm{~S}_{30}$ & $\mathrm{PPeF}_{70} \mathrm{I}_{50} \mathrm{~S}_{30}$ \\
\hline Pencil hardness & EN13523-4 & $\mathrm{H}$ & $2 \mathrm{H}$ & $3 \mathrm{H}$ & $\mathrm{H}$ & $\mathrm{H}$ \\
\hline Gloss top coat & 13523-2 & 35 & 39 & 35 & 40 & 39 \\
\hline Reverse impact $80^{\prime \prime} \mathrm{lb}$ & $13523-5$ & $\begin{array}{l}\text { Moderate } \\
\text { cracking }\end{array}$ & $\begin{array}{l}\text { Moderate } \\
\text { cracking }\end{array}$ & $\begin{array}{l}\text { Moderate } \\
\text { cracking }\end{array}$ & $\begin{array}{c}\text { Slight } \\
\text { cracking }\end{array}$ & $\begin{array}{l}\text { Moderate } \\
\text { cracking }\end{array}$ \\
\hline Erichsen $7.5 \mathrm{~mm}$ & $13523-6$ & $\begin{array}{l}\text { Moderate } \\
\text { cracking }\end{array}$ & $\begin{array}{l}\text { Severe } \\
\text { cracking }\end{array}$ & $\begin{array}{l}\text { Severe } \\
\text { cracking }\end{array}$ & $\begin{array}{l}\text { Slight } \\
\text { cracking }\end{array}$ & No cracking \\
\hline T-bend (no tape pick off) & $13523-7$ & $0.5 \mathrm{~T}^{\circ}$ & $1 \mathrm{~T}$ & $1.5 \mathrm{~T}$ & $0 \mathrm{~T}$ & $1 \mathrm{~T}$ \\
\hline T-Bend no cracking & $13523-7$ & $3 \mathrm{~T}$ & $5 \mathrm{~T}$ & $6 \mathrm{~T}$ & $2.5 \mathrm{~T}$ & $5 \mathrm{~T}$ \\
\hline MEK $^{\mathrm{a}}$ rubs primer & $\begin{array}{c}\text { BSSP } \\
3.522 .11\end{array}$ & 110 & 110 & 110 & 110 & 110 \\
\hline $\mathrm{T}_{\mathrm{g}},{ }^{\circ} \mathrm{C}$ (onset/midpoint) & & $28 / 35$ & $53 / 66$ & $51 / 53$ & $27 / 34$ & $53 / 67$ \\
\hline Microhardness, $\mathrm{N} \cdot \mathrm{m}^{-2}$ & & 216 & 237 & 287 & 190 & 270 \\
\hline
\end{tabular}

${ }^{a}$ Methyl ethyl ketone.

Table 6. Physical test results on white paints based on polyesters $\mathrm{PPeF}_{85} \mathrm{I}_{10} \mathrm{~S}_{15}, \mathrm{PPeF}_{85} \mathrm{I}_{30} \mathrm{~S}_{15}$, $\mathrm{PPeF}_{85} \mathrm{I}_{50} \mathrm{~S}_{15}, \mathrm{PPF}_{85} \mathrm{I}_{30} \mathrm{~S}_{15}$ and the standard reference resin $\mathrm{R}$.

\begin{tabular}{|c|c|c|c|c|c|c|}
\hline Test & Standard & $\mathbf{R}$ & $\mathrm{PPeF}_{85} \mathrm{I}_{10} \mathrm{~S}_{15}$ & $\mathrm{PPeF}_{85} \mathrm{I}_{30} \mathrm{~S}_{15}$ & $\mathrm{PPeF}_{85} \mathrm{I}_{50} \mathrm{~S}_{15}$ & $\mathrm{PPF}_{85} \mathrm{I}_{30} \mathrm{~S}_{15}$ \\
\hline Pencil hardness & EN13523-4 & $\mathrm{H}$ & $\mathrm{H}$ & $\mathrm{F}$ & $2 \mathrm{H}$ & $\mathrm{H}$ \\
\hline Gloss top coat & 13523-2 & 35 & 40 & 43 & 38 & 39 \\
\hline Reverse impact $80^{\prime \prime} \mathrm{lb}$ & $13523-5$ & $\begin{array}{l}\text { Moderate } \\
\text { cracking }\end{array}$ & No cracking & $\begin{array}{l}\text { Moderate } \\
\text { cracking }\end{array}$ & $\begin{array}{c}\text { Severe } \\
\text { cracking }\end{array}$ & $\begin{array}{c}\text { Slight } \\
\text { cracking }\end{array}$ \\
\hline Erichsen $7.5 \mathrm{~mm}$ & $13523-6$ & $\begin{array}{l}\text { Moderate } \\
\text { cracking }\end{array}$ & No cracking & No cracking & $\begin{array}{l}\text { Severe } \\
\text { cracking }\end{array}$ & $\begin{array}{l}\text { Slight } \\
\text { cracking }\end{array}$ \\
\hline T-bend (no tape pick off) & $13523-7$ & $0.5 \mathrm{~T}$ & $1.5 \mathrm{~T}$ & $1.5 \mathrm{~T}$ & $1 \mathrm{~T}$ & $1.5 \mathrm{~T}$ \\
\hline T-Bend no cracking & $13523-7$ & $3 \mathrm{~T}$ & $1 \mathrm{~T}$ & $2 \mathrm{~T}$ & $5.5 \mathrm{~T}$ & $2.5 \mathrm{~T}$ \\
\hline MEK rubs primer & $\begin{array}{c}\text { BSSP } \\
3.522 .11\end{array}$ & 110 & 110 & 110 & 110 & 110 \\
\hline $\mathrm{T}_{\mathrm{g}},{ }^{\circ} \mathrm{C}$ (onset/midpoint) & & $28 / 35$ & $26 / 32$ & $34 / 42$ & $58 / 69$ & $29 / 34$ \\
\hline Microhardness, $\mathrm{N} \cdot \mathrm{m}^{-2}$ & & 216 & 174 & 287 & 299 & 169 \\
\hline
\end{tabular}

\section{Conclusions}

We successfully diversified and enhanced the properties of novel biomass-derived polyester coatings based on FDCA, succinic acid, and either 1,3-propanediol or 1,5-pentanediol by incorporating isosorbide into the polyesters' backbone. Depending on the concentration of isosorbide, the molecular weight of the polyesters could be tuned from 700 to 10,200 Da. In general, the molecular weight decreased as the isosorbide content increased. This behavior could be attributed to the difference in reactivity of the $\mathrm{OH}$ groups present in isosorbide. The thermal results suggested that a minimum $50 \mathrm{~mol} \%$ isosorbide is needed to achieve glass transition temperatures above $0{ }^{\circ} \mathrm{C}$ and above room temperature. The $\mathrm{T}_{\mathrm{g}}$ could vary approximately 40 degrees by solely adjusting the molar isosorbide concentration.

Paint testing results showed that the best isosorbide resins for coil coating applications were $\mathrm{PPeF}_{85} \mathrm{I}_{30} \mathrm{~S}_{15}$ and $\mathrm{PPeF}_{70} \mathrm{I}_{30} \mathrm{~S}_{30}$, along with $\mathrm{PPF}_{85} \mathrm{I}_{30} \mathrm{~S}_{15}$. The consideration of bioderived 1,5-pentanediol as a main building block opens the possibility towards the development of flexible coatings but with better hardness than currently used diols, such as 1,6-hexanediol, enhanced by the presence of FDCA and isosorbide.

The inclusion of the carbohydrate-derived diol isosorbide to our coatings did promote better performance in terms of thermomechanical properties, and allowed for the tuning of fully biomass-derived resins that could easily replace the current petrochemical-derived ones in different applications, with controlled molecular weights and glass transition temperatures. Exterior durability testing for top coats would still be needed, but our bio-derived coatings could be used as backing coatings and interior finishes. Future work however needs to be done in terms of the variables effects on the $T_{g}$, the identification of the nature of the different oligomers or cyclic structures formed during the polymerization, as well as a kinetic study to optimize the reaction conditions to overcome the isosorbide's low-reactive nature. 
Supplementary Materials: The following are available online at http:/ /www.mdpi.com/2073-4360/10/6/600/s1, Figure S1: ${ }^{1} \mathrm{H}$ NMR of isosorbide monomer, Table S1: Monomer Charge for PPFIS Polyesters, Table S2: Monomer Charge for PPeFIS polyesters, Figure S2: ${ }^{13} \mathrm{C}$ NMR of $\mathrm{PPeF}_{15} \mathrm{I}_{50} \mathrm{~S}_{85}$, Figure S3: HSQC of PPeF $15 \mathrm{I}_{50} \mathrm{~S}_{85}$, Figure S4: GPC chromatogram of polyesters PPeFIS with $30 \mathrm{~mol} \%$ isosorbide, Figure S5: GPC chromatogram of polyesters PPeFIS with $50 \mathrm{~mol} \%$ isosorbide, Figure S6: GPC chromatogram of polyesters $\mathrm{PPF}_{15} \mathrm{IS}_{85}$ and $\mathrm{PPF}_{30} \mathrm{IS}_{70}$, Table S3: Thermal transitions of PPFIS measured by DSC, Figure S7: DSC thermogram of $\mathrm{PPeF}_{15} \mathrm{IS}_{85}$, Figure S8: DSC thermogram of $\mathrm{PPF}_{30} \mathrm{IS}_{70}$, Figure S9: First heating scan at $10{ }^{\circ} \mathrm{C} / \mathrm{min}$ for polyesters $\mathrm{PPF}_{70} \mathrm{IS}_{30}$, Figure S10: $\mathrm{T}_{\mathrm{g}}-\mathrm{M}_{\mathrm{n}}-\mathrm{mol} \%$ isosorbide relationship for $\mathrm{PPeF}_{5} \mathrm{IS}_{85}$, Figure S11: $\mathrm{T}_{\mathrm{g}}-\mathrm{M}_{\mathrm{n}}-\mathrm{mol} \%$ isosorbide relationship for PPeF1 $1_{30} \mathrm{IS}_{70}$, Table S4: Characteristic decomposition temperatures $\mathrm{T}_{\mathrm{d} 1}, \mathrm{~T}_{\mathrm{dmax}}$ and weight loss $\%$ of PPeFIS, Table S5: Characteristic decomposition temperatures $\mathrm{T}_{\mathrm{d} 1}, \mathrm{~T}_{\mathrm{d} 2}$ and $\mathrm{T}_{\mathrm{dmax}}$ and weight loss $\%$ of PPFIS, Figure S12: TGA thermograms for $\mathrm{PPeF}_{15} \mathrm{IS}_{85}$ and $\mathrm{PPeF}_{30} \mathrm{IS}_{70}$.

Author Contributions: M.L.-R. conceived and designed the experiments; M.L.-R. and J.R.C.-M. performed the experiments; M.L.-R., J.R.C.-M., R.M., and S.W. analyzed the data; R.M. and S.W. contributed reagents/materials/analysis tools; M.L.-R. and J.A.L.-S wrote the paper; J.A.L.-S. reviewed and approved the paper.

Acknowledgments: All authors are grateful to the EPSRC for funding support. Mónica Lomelí-Rodríguez is grateful to Consejo Nacional de Ciencia y Tecnología (CONACYT) for funding support and to Becker Industrial Coatings Ltd. in Liverpool for the valuable discussions and the facilities provided.

Conflicts of Interest: The authors declare no conflict of interest. The founding sponsors had no role in the design of the study; in the collection, analyses, or interpretation of data; in the writing of the manuscript, and in the decision to publish the results.

\section{References}

1. Siyab, N.; Tenbusch, S.; Willis, S.; Lowe, C.; Maxted, J. Going Green: Making reality match ambition for sustainable coil coatings. J. Coat. Technol. Res. 2016, 13, 629-643. [CrossRef]

2. Lomelí-Rodríguez, M.; Martín-Molina, M.; Jiménez-Pardo, M.; Nasim-Afzal, Z.; Cauët, S.I.; Davies, T.E.; Rivera-Toledo, M.; Lopez-Sanchez, J.A. Synthesis and kinetic modeling of biomass-derived renewable polyesters. J. Polym. Sci. Part A Polym. Chem. 2016, 54, 2876-2887. [CrossRef]

3. Lomelí-Rodríguez, M.; Rivera-Toledo, M.; López-Sánchez, J.A. Optimum Batch-Reactor Operation for the Synthesis of Biomass-Derived Renewable Polyesters. Ind. Eng. Chem. Res. 2017, 56, 549-559. [CrossRef]

4. Lomelí-Rodríguez, M.; Rivera-Toledo, M.; López-Sánchez, J.A. Process Intensification of the Synthesis of Biomass-Derived Renewable Polyesters: Reactive Distillation and Divided Wall Column Polyesterification. Ind. Eng. Chem. Res. 2017, 56, 3017-3032. [CrossRef]

5. Gubbels, E.; Drijfhout, J.P.; Posthuma-van Tent, C.; Jasinska-Walc, L.; Noordover, B.A.J.; Koning, C.E. Bio-based semi-aromatic polyesters for coating applications. Prog. Organ. Coat. 2014, 77, 277-284. [CrossRef]

6. Naves, A.F.; Fernandes, H.T.C.; Immich, A.P.S.; Catalani, L.H. Enzymatic syntheses of unsaturated polyesters based on isosorbide and isomannide. J. Polym. Sci. Part A Polym. Chem. 2013, 51, 3881-3891. [CrossRef]

7. Feng, X.; East, A.J.; Hammond, W.B.; Zhang, Y.; Jaffe, M. Overview of advances in sugar-based polymers. Polym. Adv. Technol. 2011, 22, 139-150. [CrossRef]

8. Fenouillot, F.; Rousseau, A.; Colomines, G.; Saint-Loup, R.; Pascault, J.-P. Polymers from renewable 1, 4: 3, 6-dianhydrohexitols (isosorbide, isomannide and isoidide): A review. Prog. Polym. Sci. 2010, 35, 578-622. [CrossRef]

9. Rose, M.; Palkovits, R. Isosorbide as a renewable platform chemical for versatile applications-Quo Vadis? ChemSusChem 2012, 5, 167-176. [CrossRef] [PubMed]

10. Flèche, G.; Huchette, M. Isosorbide. Preparation, Properties and Chemistry. Starch Stärke 1986, 38, 26-30. [CrossRef]

11. Fertier, L.; Ibert, M.; Buffe, C.; Saint-Loup, R.; Joly-Duhamel, C.; Robin, J.J.; Giani, O. New biosourced UV curable coatings based on isosorbide. Prog. Organ. Coat. 2016, 99, 393-399. [CrossRef]

12. Zhou, C.; Wei, Z.; Yu, Y.; Wang, Y.; Li, Y. Biobased copolyesters from renewable resources: Synthesis and crystallization kinetics of poly(propylene sebacate-co-isosorbide sebacate). RSC Adv. 2015, 5, 68688-68699. [CrossRef]

13. Wang, G.; Jiang, M.; Zhang, Q.; Wang, R.; Zhou, G. Biobased copolyesters: Synthesis, crystallization behavior, thermal and mechanical properties of poly(ethylene glycol sebacate-co-ethylene glycol 2,5-furan dicarboxylate). RSC Adv. 2017, 7, 13798-13807. [CrossRef] 
14. Noordover, B.A.; Duchateau, R.; van Benthem, R.A.; Ming, W.; Koning, C.E. Enhancing the functionality of biobased polyester coating resins through modification with citric acid. Biomacromolecules 2007, 8, 3860-3870. [CrossRef] [PubMed]

15. Kricheldorf, H.R.; Weidner, S.M. High $\mathrm{T}$ g copolyesters of lactide, isosorbide and isophthalic acid. Eur. Polym. J. 2013, 49, 2293-2302. [CrossRef]

16. Garaleh, M.; Yashiro, T.; Kricheldorf, H.R.; Simon, P.; Chatti, S. (Co-) Polyesters Derived from Isosorbide and 1, 4-Cyclohexane Dicarboxylic Acid and Succinic Acid. Macromol. Chem. Phys. 2010, 211, 1206-1214. [CrossRef]

17. Park, H.-S.; Gong, M.-S.; Knowles, J.C. Synthesis and biocompatibility properties of polyester containing various diacid based on isosorbide. J. Biomater. Appl. 2012, 27, 99-109. [CrossRef] [PubMed]

18. Goerz, O.; Ritter, H. Polymers with shape memory effect from renewable resources: Crosslinking of polyesters based on isosorbide, itaconic acid and succinic acid. Polym. Int. 2013, 62, 709-712. [CrossRef]

19. Noordover, B.A.; van Staalduinen, V.G.; Duchateau, R.; Koning, C.E.; van Benthem, R.A.; Mak, M.; Heise, A.; Frissen, A.E.; van Haveren, J. Co-and terpolyesters based on isosorbide and succinic acid for coating applications: Synthesis and characterization. Biomacromolecules 2006, 7, 3406-3416. [CrossRef] [PubMed]

20. Wei, Z.; Zhou, C.; Yu, Y.; Li, Y. Biobased copolyesters from renewable resources: Synthesis and crystallization behavior of poly (decamethylene sebacate-co-isosorbide sebacate). RSC Adv. 2015, 5, 42777-42788. [CrossRef]

21. Kasmi, N.; Majdoub, M.; Papageorgiou, G.Z.; Bikiaris, D.N. Synthesis and crystallization of new fully renewable resources-based copolyesters: Poly(1,4-cyclohexanedimethanol-co-isosorbide 2,5-furandicarboxylate). Polym. Degrad. Stab. 2018, 152, 177-190. [CrossRef]

22. Terzopoulou, Z.; Kasmi, N.; Tsanaktsis, V.; Doulakas, N.; Bikiaris, D.N.; Achilias, D.S.; Papageorgiou, G.Z. Synthesis and Characterization of Bio-Based Polyesters: Poly(2-methyl-1,3-propylene-2,5-furanoate), Poly(isosorbide-2,5-furanoate), Poly(1,4-cyclohexanedimethylene-2,5-furanoate). Materials 2017, $10,801$. [CrossRef] [PubMed]

23. Van Haveren, J.; Oostveen, E.A.; Miccichè, F.; Noordover, B.A.J.; Koning, C.E.; van Benthem, R.A.T.M.; Frissen, A.E.; Weijnen, J.G.J. Resins and additives for powder coatings and alkyd paints, based on renewable resources. J. Coat. Technol. Res. 2007, 4, 177-186. [CrossRef]

24. Gioia, C.; Vannini, M.; Marchese, P.; Minesso, A.; Cavalieri, R.; Colonna, M.; Celli, A. Sustainable polyesters for powder coating applications from recycled PET, isosorbide and succinic acid. Green Chem. 2014, 16, 1807-1815. [CrossRef]

25. Jacquel, N.; Saint-Loup, R.; Pascault, J.-P.; Rousseau, A.; Fenouillot, F. Bio-based alternatives in the synthesis of aliphatic-aromatic polyesters dedicated to biodegradable film applications. Polymer 2015, 59, $234-242$. [CrossRef]

26. Bersot, J.C.; Jacquel, N.; Saint-Loup, R.; Fuertes, P.; Rousseau, A.; Pascault, J.P.; Spitz, R.; Fenouillot, F.; Monteil, V. Efficiency Increase of Poly (ethylene terephthalate-co-isosorbide terephthalate) Synthesis using Bimetallic Catalytic Systems. Macromol. Chem. Phys. 2011, 212, 2114-2120. [CrossRef]

27. Gandini, A.; Silvestre, A.J.; Neto, C.P.; Sousa, A.F.; Gomes, M. The furan counterpart of poly (ethylene terephthalate): An alternative material based on renewable resources. J. Polym. Sci. Part A Polym. Chem. 2009, 47, 295-298. [CrossRef]

28. Jiang, M.; Liu, Q.; Zhang, Q.; Ye, C.; Zhou, G. A series of furan-aromatic polyesters synthesized via direct esterification method based on renewable resources. J. Polym. Sci. Part A Polym. Chem. 2012, 50, 1026-1036. [CrossRef]

29. Papageorgiou, G.Z.; Tsanaktsis, V.; Papageorgiou, D.G.; Exarhopoulos, S.; Papageorgiou, M.; Bikiaris, D.N. Evaluation of polyesters from renewable resources as alternatives to the current fossil-based polymers. Phase transitions of poly (butylene 2, 5-furan-dicarboxylate). Polymer 2014, 55, 3846-3858. [CrossRef]

30. Sousa, A.; Fonseca, A.; Serra, A.; Freire, C.; Silvestre, A.; Coelho, J. New unsaturated copolyesters based on 2, 5-furandicarboxylic acid and their crosslinked derivatives. Polym. Chem. 2016, 7, 1049-1058. [CrossRef]

31. Vannini, M.; Marchese, P.; Celli, A.; Lorenzetti, C. Fully biobased poly (propylene 2, 5-furandicarboxylate) for packaging applications: Excellent barrier properties as a function of crystallinity. Green Chem. 2015, 17, 4162-4166. [CrossRef]

32. Tsanaktsis, V.; Terzopoulou, Z.; Nerantzaki, M.; Papageorgiou, G.Z.; Bikiaris, D.N. New poly (pentylene furanoate) and poly (heptylene furanoate) sustainable polyesters from diols with odd methylene groups. Mater. Lett. 2016, 178, 64-67. [CrossRef] 
33. Terzopoulou, Z.; Tsanaktsis, V.; Bikiaris, D.N.; Exarhopoulos, S.; Papageorgiou, D.G.; Papageorgiou, G.Z. Biobased poly (ethylene furanoate-co-ethylene succinate) copolyesters: Solid state structure, melting point depression and biodegradability. RSC Adv. 2016, 6, 84003-84015. [CrossRef]

34. Burgess, S.K.; Leisen, J.E.; Kraftschik, B.E.; Mubarak, C.R.; Kriegel, R.M.; Koros, W.J. Chain mobility, thermal, and mechanical properties of poly (ethylene furanoate) compared to poly (ethylene terephthalate). Macromolecules 2014, 47, 1383-1391. [CrossRef]

35. Terzopoulou, Z.; Karakatsianopoulou, E.; Kasmi, N.; Tsanaktsis, V.; Nikolaidis, N.; Kostoglou, M.; Papageorgiou, G.Z.; Lambropoulou, D.A.; Bikiaris, D.N. Effect of catalyst type on molecular weight increase and coloration of poly(ethylene furanoate) biobased polyester during melt polycondensation. Polym. Chem. 2017, 8, 6895-6908. [CrossRef]

36. Wu, L.; Mincheva, R.; Xu, Y.; Raquez, J.-M.; Dubois, P. High molecular weight poly (butylene succinate-co-butylene furandicarboxylate) copolyesters: From catalyzed polycondensation reaction to thermomechanical properties. Biomacromolecules 2012, 13, 2973-2981. [CrossRef] [PubMed]

37. Hbaieb, S.; Kammoun, W.; Delaite, C.; Abid, M.; Abid, S.; El Gharbi, R. New copolyesters containing aliphatic and bio-based furanic units by bulk copolycondensation. J. Macromol. Sci. Part A 2015, 52, 365-373. [CrossRef]

38. Yu, Z.; Zhou, J.; Cao, F.; Wen, B.; Zhu, X.; Wei, P. Chemosynthesis and characterization of fully biomass-based copolymers of ethylene glycol, 2, 5-furandicarboxylic acid, and succinic acid. J. Appl. Polym. Sci. 2013, 130, 1415-1420. [CrossRef]

39. Papageorgiou, G.Z.; Papageorgiou, D.G.; Tsanaktsis, V.; Bikiaris, D.N. Synthesis of the bio-based polyester poly (propylene 2, 5-furan dicarboxylate). Comparison of thermal behavior and solid state structure with its terephthalate and naphthalate homologues. Polymer 2015, 62, 28-38. [CrossRef]

40. Matos, M.; Sousa, A.F.; Fonseca, A.C.; Freire, C.S.; Coelho, J.F.; Silvestre, A.J. A New Generation of Furanic Copolyesters with Enhanced Degradability: Poly (ethylene 2, 5-furandicarboxylate)-co-poly (lactic acid) Copolyesters. Macromol. Chem. Phys. 2014, 215, 2175-2184. [CrossRef]

41. Storbeck, R.; Ballauff, M. Synthesis and properties of polyesters based on 2, 5-furandicarboxylic acid and 1, 4: 3, 6-dianhydrohexitols. Polymer 1993, 34, 5003-5006. [CrossRef]

42. Wu, J.; Eduard, P.; Thiyagarajan, S.; Noordover, B.A.; van Es, D.S.; Koning, C.E. Semi-Aromatic Polyesters Based on a Carbohydrate-Derived Rigid Diol for Engineering Plastics. ChemSusChem 2015, 8, 67-72. [CrossRef] [PubMed]

43. Terzopoulou, Z.; Tsanaktsis, V.; Nerantzaki, M.; Papageorgiou, G.Z.; Bikiaris, D.N. Decomposition mechanism of polyesters based on 2,5-furandicarboxylic acid and aliphatic diols with medium and long chain methylene groups. Polym. Degrad. Stab. 2016, 132, 127-136. [CrossRef]

44. Papageorgiou, G.Z.; Guigo, N.; Tsanaktsis, V.; Papageorgiou, D.G.; Exarhopoulos, S.; Sbirrazzuoli, N.; Bikiaris, D.N. On the bio-based furanic polyesters: Synthesis and thermal behavior study of Poly (octylene furanoate) using Fast and Temperature Modulated Scanning Calorimetry. Eur. Polym. J. 2015, 68, 115-127. [CrossRef]

45. Tsanaktsis, V.; Vouvoudi, E.; Papageorgiou, G.Z.; Papageorgiou, D.G.; Chrissafis, K.; Bikiaris, D.N. Thermal degradation kinetics and decomposition mechanism of polyesters based on 2, 5-furandicarboxylic acid and low molecular weight aliphatic diols. J. Anal. Appl. Pyrolysis 2015, 112, 369-378. [CrossRef]

46. Terzopoulou, Z.; Tsanaktsis, V.; Nerantzaki, M.; Achilias, D.S.; Vaimakis, T.; Papageorgiou, G.Z.; Bikiaris, D.N. Thermal degradation of biobased polyesters: Kinetics and decomposition mechanism of polyesters from 2, 5-furandicarboxylic acid and long-chain aliphatic diols. J. Anal. Appl. Pyrolysis 2016, 117, 162-175. [CrossRef]

47. Papageorgiou, G.Z.; Papageorgiou, D.G.; Terzopoulou, Z.; Bikiaris, D.N. Production of bio-based 2, 5-furan dicarboxylate polyesters: Recent progress and critical aspects in their synthesis and thermal properties. Eur. Polym. J. 2016, 83, 202-229. [CrossRef]

48. Oldring, P.K.; Tuck, N. Resins for Surface Coatings, Alkyds \& Polyesters; John Wiley \& Sons: Hoboken, NJ, USA, 2000; Volume 2.

49. Brentzel, Z.J.; Barnett, K.J.; Huang, K.; Maravelias, C.T.; Dumesic, J.A.; Huber, G.W. Chemicals from Biomass: Combining Ring-Opening Tautomerization and Hydrogenation Reactions to Produce 1,5-Pentanediol from Furfural. ChemSusChem 2017, 10, 1351-1355. [CrossRef] [PubMed]

50. Sun, D.; Sato, S.; Ueda, W.; Primo, A.; Garcia, H.; Corma, A. Production of C4 and C5 alcohols from biomass-derived materials. Green Chem. 2016, 18, 2579-2597. [CrossRef] 
51. Huang, K.; Brentzel, Z.J.; Barnett, K.J.; Dumesic, J.A.; Huber, G.W.; Maravelias, C.T. Conversion of Furfural to 1,5-Pentanediol: Process Synthesis and Analysis. ACS Sust. Chem. Eng. 2017, 5, 4699-4706. [CrossRef]

52. Chatterjee, M.; Ishizaka, T.; Kawanami, H. Hydrogenation of 5-hydroxymethylfurfural in supercritical carbon dioxide-water: A tunable approach to dimethylfuran selectivity. Green Chem. 2014, 16, 1543-1551. [CrossRef]

53. Koso, S.; Furikado, I.; Shimao, A.; Miyazawa, T.; Kunimori, K.; Tomishige, K. Chemoselective hydrogenolysis of tetrahydrofurfuryl alcohol to 1, 5-pentanediol. Chem. Commun. 2009, 2035-2037. [CrossRef] [PubMed]

54. Liu, S.; Amada, Y.; Tamura, M.; Nakagawa, Y.; Tomishige, K. One-pot selective conversion of furfural into 1, 5-pentanediol over a Pd-added Ir-ReO x/SiO 2 bifunctional catalyst. Green Chem. 2014, 16, 617-626. [CrossRef]

55. Standard Test Methods for Indentation Hardness of Organic Coatings. Available online: https: / / compass. astm.org/download/D1474D1474M.4895.pdf (accessed on 15 February 2017).

56. Coil Coated Metals. Test Methods. Pencil Hardness. Available online: http://shop.bsigroup.com/ ProductDetail/?pid=000000000030268977 (accessed on 14 February 2017).

57. Standard Test Method for Specular Gloss. Available online: https://compass.astm.org/Standards/ HISTORICAL/D523-89R99.htm (accessed on 14 February 2017).

58. Standard Practice for Assessing the Solvent Resistance of Organic Coatings Using Solvent Rubs. Available online: https: / compass.astm.org/download/D5402-93R99.15287.pdf (accessed on 15 February 2015).

59. ISO 14577-1:2015 Metallic Materials_-Instrumented Indentation Test for Hardness and Materials parameters —Part 1: Test Method. Available online: https://www.iso.org/obp/ui/\#iso:std:iso:14577:-1:ed-2:v1:en (accessed on 15 February 2017).

60. Standard Test Method for Assignment of the Glass Transition Temperatures by Differential Scanning Calorimetry or Differential Thermal Analysis. Available online: https://compass.astm.org/download/ E1356-98.33431.pdf (accessed on 15 February 2017).

61. Standard Test Method for Coating Flexibility of Prepainted Sheet. Available online: https:// compass.astm. org/download/D4145.28079.pdf (accessed on 15 February 2017).

62. Allcock, H.R.; Lampe, F.W.; Mark, J.E.; Allcock, H. Contemporary Polymer Chemistry; Pearson/Prentice Hall: Upper Saddle River, NJ, USA, 2003.

63. Sadler, J.M.; Toulan, F.R.; Palmese, G.R.; La Scala, J.J. Unsaturated polyester resins for thermoset applications using renewable isosorbide as a component for property improvement. J. Appl. Polym. Sci. 2015, 132, 42315. [CrossRef]

64. Koo, J.M.; Hwang, S.Y.; Yoon, W.J.; Lee, Y.G.; Kim, S.H.; Im, S.S. Structural and thermal properties of poly(1,4-cyclohexane dimethylene terephthalate) containing isosorbide. Polym. Chem. 2015, 6, 6973-6986. [CrossRef]

65. Łukaszczyk, J.; Janicki, B.; Kaczmarek, M. Synthesis and properties of isosorbide based epoxy resin. Eur. Polym. J. 2011, 47, 1601-1606. [CrossRef]

66. Zhu, Y.; Molinier, V.; Durand, M.; Lavergne, A.; Aubry, J.-M. Amphiphilic Properties of Hydrotropes Derived from Isosorbide: Endo/Exo Isomeric Effects and Temperature Dependence. Langmuir 2009, 25, 13419-13425. [CrossRef] [PubMed]

67. Papageorgiou, G.Z.; Achilias, D.S.; Bikiaris, D.N. Crystallization Kinetics and Melting Behaviour of the Novel Biodegradable Polyesters Poly(propylene azelate) and Poly(propylene sebacate). Macromol. Chem. Phys. 2009, 210, 90-107. [CrossRef]

68. Papageorgiou, G.Z.; Bikiaris, D.N. Crystallization and melting behavior of three biodegradable poly(alkylene succinates). A comparative study. Polymer 2005, 46, 12081-12092. [CrossRef]

69. Wang, X.; Zhou, J.; Li, L. Multiple melting behavior of poly(butylene succinate). Eur. Polym. J. 2007, 43, 3163-3170. [CrossRef]

70. Gunaratne, L.M.W.K.; Shanks, R.A. Multiple melting behaviour of poly(3-hydroxybutyrate-co-hydroxyvalerate) using step-scan DSC. Eur. Polym. J. 2005, 41, 2980-2988. [CrossRef]

71. Song, P.; Chen, G.; Wei, Z.; Zhang, W.; Liang, J. Calorimetric analysis of the multiple melting behavior of melt-crystallized poly(L-lactic acid) with a low optical purity. J. Therm. Anal. Calorim. 2013, 111, 1507-1514. [CrossRef] 
72. Chatti, S.; Weidner, S.M.; Fildier, A.; Kricheldorf, H.R. Copolyesters of isosorbide, succinic acid, and isophthalic acid: Biodegradable, high Tg engineering plastics. J. Polym. Sci. Part A Polym. Chem. 2013, 51, 2464-2471. [CrossRef]

73. Beyler, C.L.; Hirschler, M.M. Thermal decomposition of polymers. In SFPE Handbook of Fire Protection Engineering; Springer: Berlin, Germany, 2002; p. 32.

74. Montaudo, G.; Puglisi, C.; Samperi, F. Primary thermal degradation mechanisms of PET and PBT. Polym. Degrad. Stab. 1993, 42, 13-28. [CrossRef]

75. Goldfarb, I.J.; McGuchan, R. Thermal Degradation of Polyesters. 1. Aliphatic Polymers; DTIC Document; DTIC: Fort Belvoir, VA, USA, 1968.

(C) 2018 by the authors. Licensee MDPI, Basel, Switzerland. This article is an open access article distributed under the terms and conditions of the Creative Commons Attribution (CC BY) license (http://creativecommons.org/licenses/by/4.0/). 